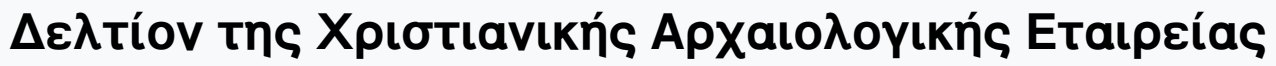

Tó 12 (1986)

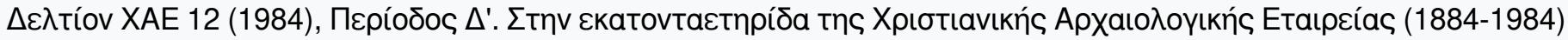

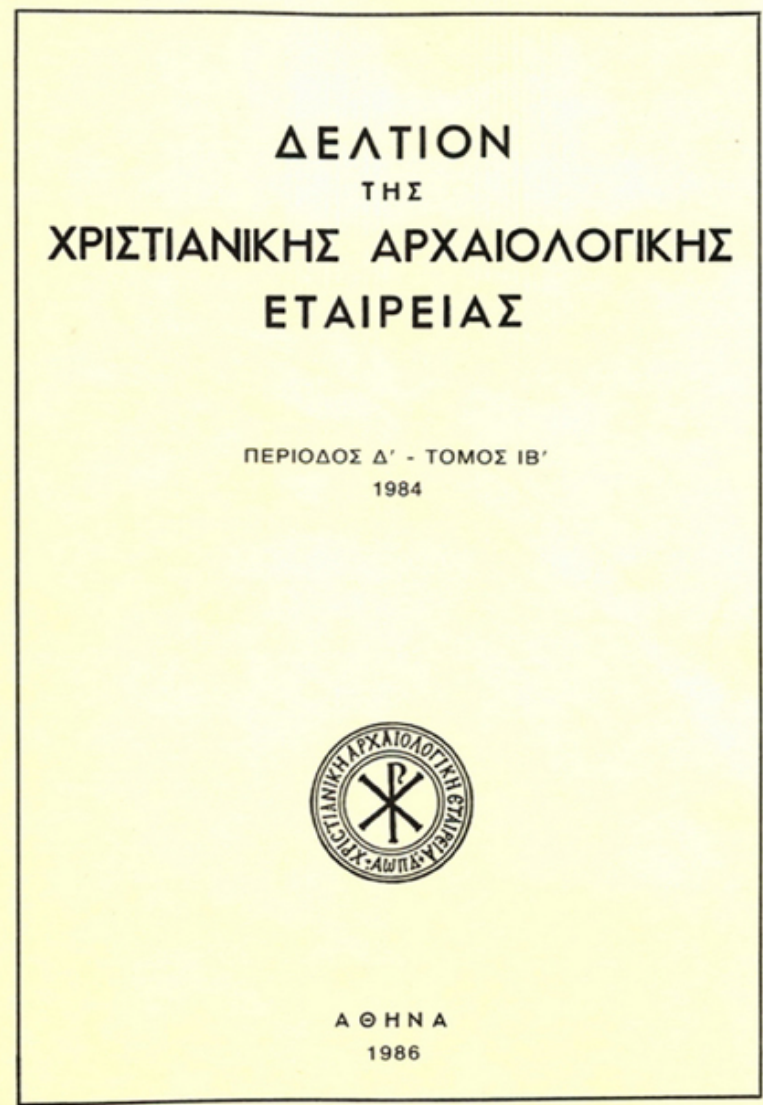

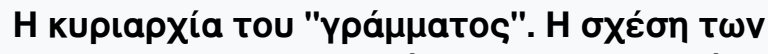

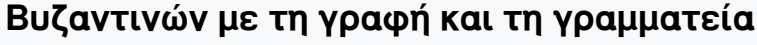

Herbert HUNGER

doi: $\underline{10.12681 / \text { dchae. } 945}$

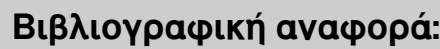

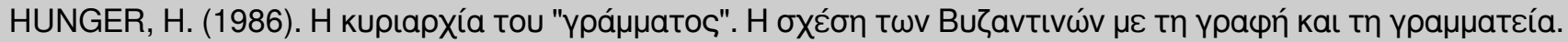

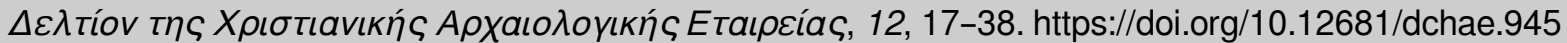




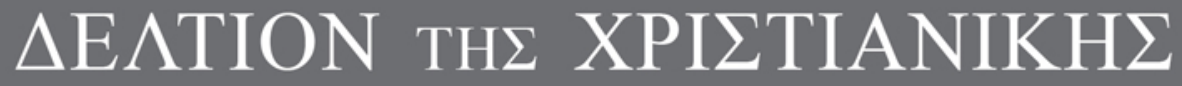 APXAIO $\Lambda$ OГIKH $\Sigma$ ETAIPEIA $\Sigma$}

Die Herrschaft des "Buchstabens". Das Verhältnis der Byzantiner zu Schrift- und Kanzleiwesen

Herbert HUNGER

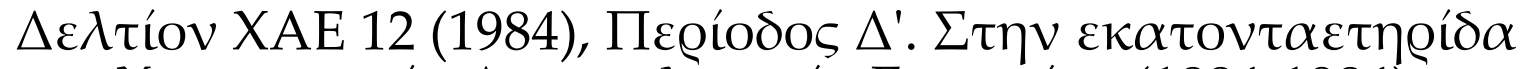

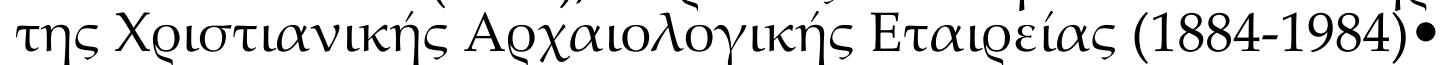
$\sum \varepsilon \lambda .17-38$

A@HNA 1986 


\section{DIE HERRSCHAFT DES "BUCHSTABENS". DAS VERHÄLTNIS DER BYZANTINER ZU SCHRIFT- UND KANZLEIWESEN}

Woher kommt es, daß Menschen, die ihren Namen nicht wie Politiker, Sportler und Künstler täglich in der Zeitung lesen können, überrascht bis betroffen sind, wenn sie beim Lesen unerwartet auf die Buchstabenkombination stoßen, die ihren Namen ausmacht? Zumindest wird einem für den Bruchteil einer Sekunde eine unbeabsichtigte Aufmerksamkeit bewußt, wenn das Auge die vertraute Buchstabenkonstellation in einem Text ertastet. Diese unwillkürliche Irritation, die wohl in die Zeit vor der Erfindung des Buchdrucks zurückreicht, kann man vielleicht als ein atavistisches Symptom ansehen. Der Buchstabe übte schon immer, seit der Einführung einer Buchstabenschrift, eine besondere Faszination aus.

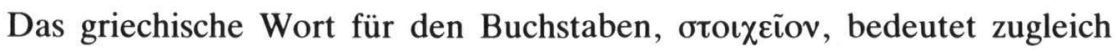
soviel wie Element, natürlich nicht nur des Alphabets, sondern auch Baustein des Kosmos. Nur weil man dem Buchstaben auch magische Kräfte zuschrieb, konnte sich bereits in der Antike die Verwendung von sogenannten Zaubercharakteren, mehr oder weniger entstellten Buchstaben, weit verbreiten. Mystik und Magie bemächtigten sich der Buchstaben auf verschiedenen Wegen im gesamten Mittelmeerraum, der damaligen Oikumene ${ }^{1}$. Es ist höchst

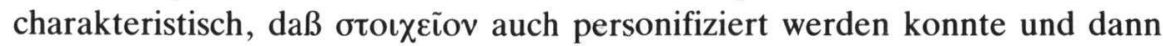
etwa die Bedeutung von Elementargeist oder Kosmokrator erhielt. So halten

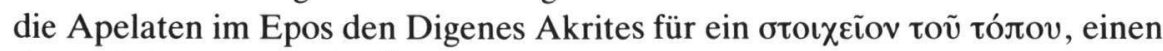
dämonischen genius $\operatorname{loci}^{2}$.

Über einzelne Vokale wurden sowohl philosophische als auch religiöse Betrachtungen angestellt. Plutarch schrieb über die verschiedenen Auslegungen des über dem Eingang zum Tempelbezirk von Delphi angebrachten $\mathrm{EI}^{3}$. Barsanuphios meditierte im 6. Jahrhundert über mögliche Deutungen des Buchstabens H (Eta) im Rahmen des asketischen Aufstiegs ${ }^{4}$. In Byzanz versuchte man, mit den Anfangsbuchstaben von Kaisernamen Politik zu

1. F. Dornseiff, Das Alphabet in Mystik und Magie, Lpz. - Berlin ${ }^{2} 1925$; ND Lpz. 1975. A. Berthelot, Die Macht der Schrift in Glauben und Aberglauben, Abh. Dt. Akad. Wiss. Berlin, phil.-hist. Kl. 1948/1, Berlin 1949, 1-48.

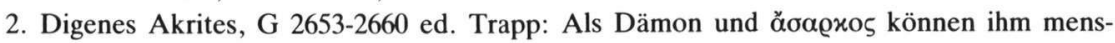
chliche Waffen nichts anhaben!

3. Plut arch, De E apud Delphos, edd. W.R. Patton, M. Pohlenz, W. Sieveking, Lpz. 1929; ${ }^{2} 1972$.

4. P. de Angelis-Noah, La méditation de Barsanuphe sur la lettre HTA, Byz. 53 (1983) 494-506. 
machen. Photios verstand es bekanntlich, sich mit Hilfe des von ihm selbst konstruierten Schlüsselwortes BEK $\Lambda$ A $\Sigma$ bei Kaiser Basileios wieder ins Licht

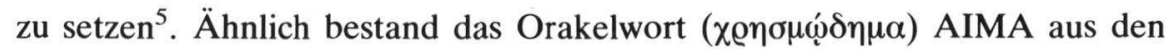
Anfangsbuchstaben der Komnenenherrscher ${ }^{6}$. Pachymeres erzählt von einer geheimnisvollen Stimme, die dreimal hintereinander das Wort MAPПOY vernehmen ließ, das aus keiner Sprache erklärt werden konnte. Die Lösung

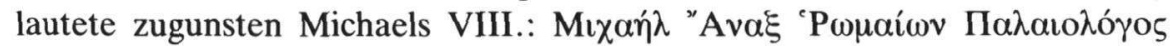

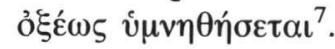

Der einzelne Buchstabe, als Initiale eines Namens, häufig mit einem zweiten Buchstaben (so bei Doppelnamen) ligiert, wurde und wird bis in unsere Tage als praktisches Zeichen für den Besitzer eines Gegenstandes verwendet. Wenn ein antiker oder mittelalterlicher Herrscher seine Initialen auf Bauwerken, etwa auf Kapitellen, auf Münzen oder in Handschriften anbringen ließ, so vertraten die Buchstaben die Persönlichkeit des Bauherrn oder Stifters. In Wien stehen noch heute verschiedene Bauten aus der Zeit Kaiser Franz Josephs I., die dessen Initialen tragen. Die Ligatur von Buchstaben führt in den Bereich des Monogramms, in dem sich Tausende von Beispielen aus Byzanz auf Siegeln und Münzen als Zeichen für den Münzherrn oder den Initiator einer Urkunde bwz. eines Briefes erhalten haben. Das Erscheinen des Monogramms auf Gegenständen oder in Räumen weist stets auf eine Art von Herrschafts- oder Besitzrecht hin. Das Christogramm und die Ligatur des Namens Maria sind allgemein bekannte Beispiele aus der Frühzeit des Christentums. An der berühmten, in der Auslegung umstrittenen Stelle

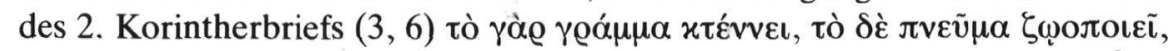
steht der "Buchstabe" jedenfalls auf der negativen Seite der Antithese ${ }^{8}$.

Seit ältesten Zeiten maß man auch dem Eigennamen besondere Bedeutung zu. Der Glaube, aus dem Namen auf Eigenschaften seines Trägers schließen zu können, verlieh im Mittelalter den etymologischen Deutungsversuchen, die übrigens schon bei Homer und Hesiod vorkommen, große Beliebtheit ${ }^{9}$.

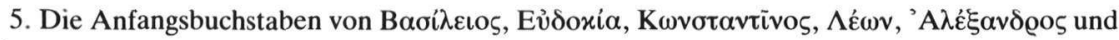
$\Sigma \tau \varepsilon \dot{\varepsilon}$ avo bildeten das Schlüsselwort für die Familie des Basileios: Ps.-Symeon 689f.; Manasses, V. 5311ff.; Glykas 522f.

6. Niketas Choniates 169 , 94f. und 1-4.

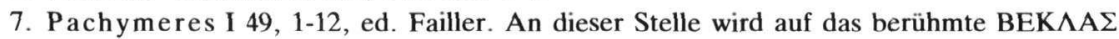
zurückverwiesen. - Ein dreifaches Pi "prophezeite" den Tod Michaels: Er war ein Palaiologe, starb in Pachomion, und zwar an einem Freitag (Paraskeue): Pachymeres II 667, 10-16, ed. Failler.

8. Vgl. auch Röm. 7, 6.

9. H. J. Lingohr, Die Bedeutung der etymologischen Namenserklärung in den Gedichten Homers und Hesiods und in den homerischen Hymnen, Diss. FU Berlin 1954; zitiert von I. Opelt, Christianisierung heidnischer Etymologien, Jb. Ant. Christ. 2 (1959) 70-85, hier 71. Vgl. mehrere Beiträge zur Festschrift für F. Ohly z. 60. Geburtstag: Verbum et signum. Bd. 1, München 1974. 


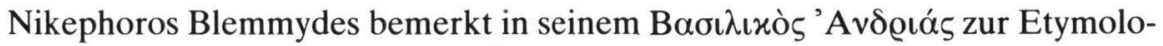

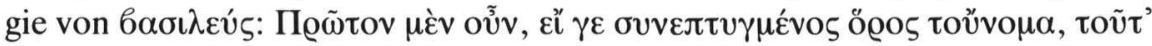

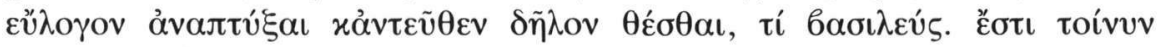

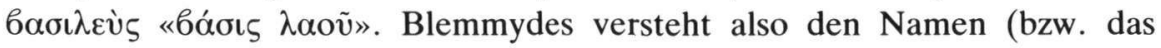
nomen) als eine implizite Definition, die sich durch Explikation ( $\alpha \dot{v} \alpha \tau \tau \hat{\jmath} \xi \alpha \iota)$ erklären läßt ${ }^{10}$. Die Namensnennung des Autors zu Beginn oder am Ende eines Textes als Zeichen des geistigen Besitzrechts (Urheberrecht) finden wir z.B. in einem der ältesten griechischen Papyri, der die "Perser" des Timotheos

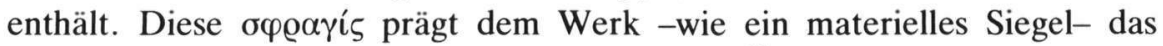
Charakteristikum der Künstlerpersönlichkeit auf ${ }^{11}$.

Zwar war man sich schon in der Antike des spielerischen Elements bewußt, das in der etymologischen Namensdeutung nicht zu übersehen ist. So weist etwa Synesios an einer Briefstelle, wenn er sich des Wortspiels X@úon५-

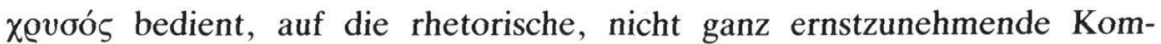
ponente der Namensdeutung hin ${ }^{12}$. Aber die Beliebtheit dieser etymologischen Namensdeutung, gerade seit der Spätantike, lehrt schon eine oberflächliche Durchsicht der hagiographischen Literatur. Nur wenige Autoren unterdrücken etymologisch-rhetorische Anspielungen bei der Namensnennung ihrer Heiligen. Romanos Melodos bediente sich dieser Art von Namensdeutungen im Rahmen rhetorischer Aggression ${ }^{13}$. Das Gleiche gilt von der Behandlung der Verfolgernamen in der hagiographischen Literatur ${ }^{14}$.

Wie einzelne Buchstaben bzw. der Eigenname das Besitzrecht ausdrücken, so herrschte umgekehrt im Bereich der Magie die Vorstellung, daß man mit Hilfe des Namens sich einer Person bemächtigen, auf sie einen, zumeist ungünstigen, Einfluß auszuüben vermag. Hier liegt der Ursprung aller Defixionen und des ganzen Namen-Zaubers. Der schon bei Platon erwähnte Bindezauber ${ }^{15}$ war noch im späten Byzanz bekannt. Die alte Zauberin im Roman Kallimachos und Chrysorrhoe schreibt böse Zaubercharaktere ( $\gamma \varrho \alpha ́ \mu-$

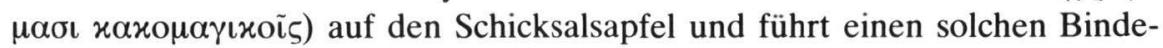

10. $\alpha v \alpha \pi \tau v \xi \xi v \tau \alpha$ steht auch bei Pachymeres I 49, 10 in analogem Zusammenhang.

11. Pap. Berol. 9875, Ende 4. Jh. v. Chr., ed. U. v. Wilamowitz-Moellendorff, Der Timotheos-Papyrus, in: Wiss. Veröff. d. Dt. Orientgesellschaft, H. 3, 1903.

12. Synesii Cyrenensis Epistolae, ed. A. Garzya, Rom 1979, S. 148, Z. 7ff. (ep. 83): ỏ $\lambda \lambda \lambda^{\prime}$ ö $\tau \iota$

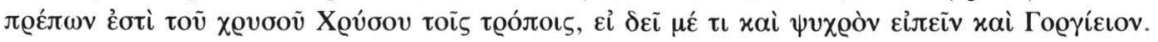

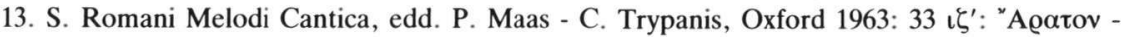

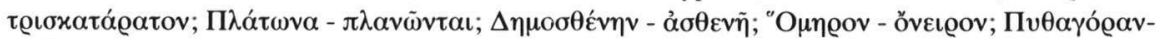

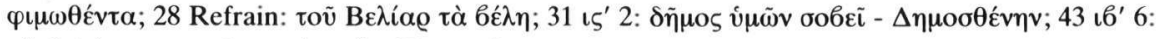

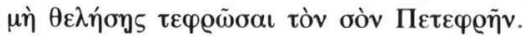

14. Beispiele bei E. Follieri, Gli appellativi dei persecutori nel sinassario di Costantinopoli,

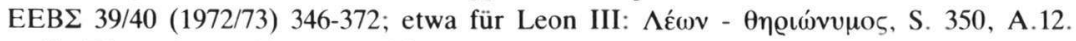

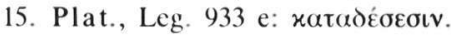


zauber durch ${ }^{16}$. Aus einigen Hunderten von Bleilamellen, die für Defixiones verwendet wurden ${ }^{17}$, und aus den rund 130 griechischen, zum Teil christlichen Zauberpapyri in der Ausgabe von Karl Preisendanz ${ }^{18}$ können wir uns ein Bild darüber machen, wie sehr breite Schichten der spätantiken Gesellschaft dem Dämonenglauben und der Magie des Buchstabens huldigten. Die Liebeszauber- und Unterwerfungszauberpapyri nennen jeweils die Namen oder setzen

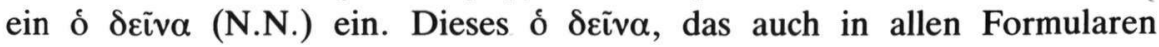
aufscheint, beweist die Wichtigkeit des Namens in der Magie.

Einer der ältesten griechischen Papyri, die wir kennen, die sogenannte Klage der Artemisia, legt Zeugnis für den Glauben einer einfachen Frau ab, $\mathrm{da} ß$ das geschriebene Wort auf die Gottheit eine zwingende, man kann auch sagen magische, Wirkung ausüben müsse. Artemisia klagt bei Oserapis und seinen Mitgöttern über ihren Gatten, der sie und die Kinder sosehr vernachlässigt, da $\beta$ er sich nicht einmal um das Begräbnis seiner kleinen Tochter kümmert; ihr Fluch paßt gut zu dem ägyptisch-griechischen Milieu am Beginn der Ptolemäerzeit ${ }^{19}$.

Die Zehntausende griechischer Papyri, die uns der Sand Ägyptens im Laufe eines Jahrhunderts beschert hat, geben vorzüglichen Aufschluß über die Verwaltung des Landes und die sozialen Verhältnisse von der Ptolemäerzeit bis in die Jahrzehnte nach der arabischen Eroberung. Wir lernen den Zentralismus und Fiskalismus des Staates kennen, der sich innerhalb dieses Jahrtausends nicht wesentlich verändert, höchstens vorübergehend perfektioniert hat. Die Bürokratie Ägyptens -es war die der Ptolemäer, später der Römer und der Byzantiner- schuf sich einen Verwaltungsapparat, der eine weitgehende Kontrolle und Erfassung der Bevölkerung ermöglichte. Ein gut funktionierendes Kanzleiwesen bildete hierfür die Voraussetzung. Schreiber in den verschiedenen Rängen sahen in Ägyptèn zu Beginn der Ptolemäerzeit schon auf eine mehrtausendjährige Vergangenheit zurück. Wir lernen aus den

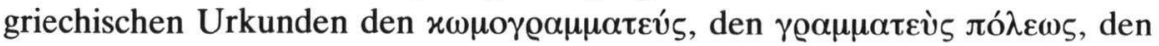

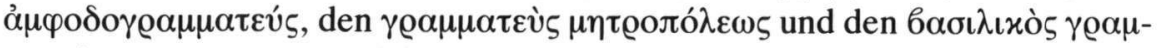

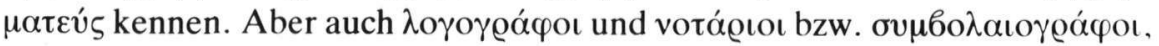

16. Le roman de Callimaque et de Chrysorrhoé, ed. M. Pichard, Paris 1956, v. 1206-1209;

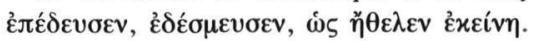

17. A. Audollent, Tabulae defixionum, Paris ${ }^{2} 1924$.

18. K. Preisendanz, Papyri Graecae Magicae. Die griechischen Zauberpapyri, Lpz. I (1928), II (1931). Bd. III wurde 1943 vernichtet; vgl. dens., Zur Überlieferung der griechischen Zauberpapyri, in: Miscellanea critica I, Lpz. 1964, 203-217. Bd. I. II Stuttgart ${ }^{2} 1973 / 74$.

19. Österr. Nationalbibl. G I; ed. U. Wilcken, Urkunden der Ptolemäerzeit, Bd. 1, Berlin 1927, 97-104; ed. K. Preisendanz, Papyri Graecae Magicae, ${ }^{2} 1973 / 74$, Nr. XL, S. 177f. Zur Paläographie (Inschriftenstil) vgl. H. Hunger, Antikes und mittelalterliches Buch- und Schriftwesen, in: Geschichte der Textüberlieferung, Bd. 1, Zürich 1961, 27-147, hier 73f. 
die dem Pagarchen unterstanden, verdienten ihr Brot mit dem Schreiberhandwerk. Während ein Großteil der Bevölkerung aus Analphabeten oder Personen mit minimalen Schreibkenntnissen bestand, wurde der reiche Bedarf der Bürokratie an geübtem Kanzleipersonal aus der Gruppe der Berufsschreiber gedeckt ${ }^{20}$. Die Ägypter hatten ein Faible für die schriftliche Abfassung von Urkunden über alle möglichen zwischenmenschlichen Beziehungen; das kam von ihrer mystischen Verehrung des geschriebenen Wortes und des Buchstabens ${ }^{21}$.

Der Bürger wurde ohne Rücksicht auf seine gesellschaftliche Stellung durch die Behörde "von der Wiege bis zur Bahre" unter Kontrolle gehalten. Zunächst gab es seit der Ptolemäerzeit neben den Geburtsurkunden aufgrund einer Meldepflicht jene Listen (census), die den Bürger schon bald nach der Geburt mit verschiedenen Personaldaten erfaßten. Sie waren die Vorbedin-

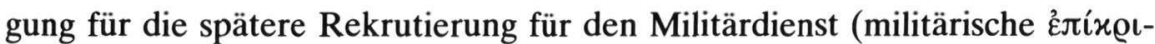
$\sigma \iota \varsigma$ ), aber auch für die Überprüfung der Vermögenswerte (fiskalische દ̇ंíx@l$\sigma \iota \varsigma)^{22}$. Für den Militärdienst trug man den wehrfähig Gewordenen in die Stammrolle ein, um seine Einberufung im Kriegsfall zu erleichtern. In den

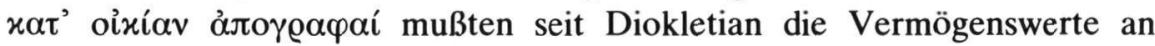
Immobilien und Mobilien, die genauen Familienverhältnisse, sowie Zahl und

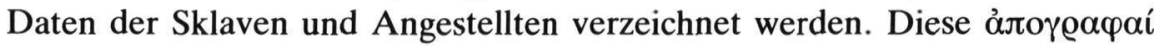
waren die Grundlage für die Bemessung der Steuerleistungen. Den Kern des Steueraufkommens bildeten der Pachtzins (Ẻx甲ó@ıov) und die Grundsteuer; dazu kam die Vermögenssteuer auf Sklaven, Vieh und Gebäude, sowie eine Kopfsteuer; aber auch Zwangsbeiträge für staatliche Einrichtungen und Gebühren für staatliche Monopole waren zu leisten. Gegenüber diesem Apparat des Staates, der auf der Schriftlichkeit eines eingespielten Kanzleibetriebs beruhte, mußten sich die einzelnen Bürger, insbesondere die den Unterschichten Angehörigen und alle Analphabeten hilflos und ausgesetzt fühlen. Behördenwillkür, die es ja auch noch in unseren Tagen -selbst in den sogenannten demokratischen Staaten- gibt, förderte Angst und Schuldgefühle auf seiten der Betroffenen.

20. Zu diesem Thema s. H. C. Youtie, AГPAMMATOs. An Aspect of Greek Society in Egypt, in: Scriptiunculae II, Amsterdam 1973, Nr. 29, S. 611-627, der betont, daß die Erstellung einer Statistik über den Analphabetismus in Ägypten derzeit noch unmöglich ist. Treffend bemerkt Youtie: Sociologically speaking, scribes were indispensable, literacy was not (a.O.619).

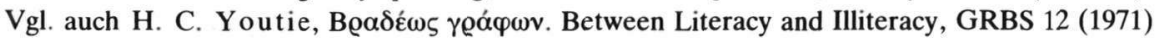
239-261. Ders., ҮПОГРАФЕҮ : The Social Impact of Illiteracy in Graeco-Roman Egypt, Zs. Pap. u. Epigr. 17 (1975) 201-222.

21. Youtie, An Aspect, a.O. 619.

22. L. Mitteis - U. Wilcken, Grundzüge und Chrestomathie der Papyruskunde I 2, Berlin Lpz. 1912, Nr. 216-220. 
Aus diesen Verhältnissen erklärt sich die weit verbeitete Steuerflucht, die

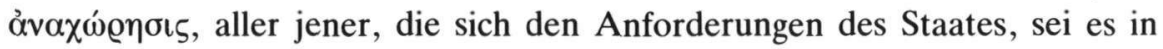
bezug auf die genannten Leistungen, sei es auf die zumeist hoch angesetzten Liturgien für vermögendere Stadtbewohner entziehen wollten. Diese schon im 1. Jahrhundert n. Chr. nachweisbare Bewegung gewann in der Spätantike an Umfang. Da die Zurückgebliebenen die der Behörde fehlenden Steuern

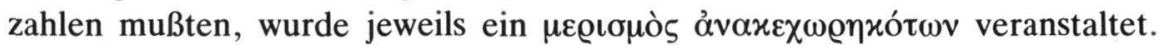
Seit dem 4. Jahrhundert suchten viele Steuerflüchtige einen Unterschlupf bei einem mächtigen Großgrundbesitzer, der sie gegen Forderungen des Staates in Schutz nehmen konnte ${ }^{23}$. Durch diese Mißstände wurden ganze Ortschaften und Gegenden in Ägypten entvölkert. Dazu kam noch die nicht unbeträchtliche Flucht von Sklaven ${ }^{24}$.

Alles was mit dem Schreiben und mit dem Kanzleiwesen zusammenhing, war für die kleinen Leute gefährlich und verdächtig. Es ist doch decouvrierend, daß das einfache Wort für etwas Handgeschriebenes, $\chi \varepsilon \iota \varrho o ́ \gamma \varrho \alpha \varphi \circ v$, in vielen Fällen mit Schuldschein zu übersetzen ist. Das gilt z.B. von der einzigen

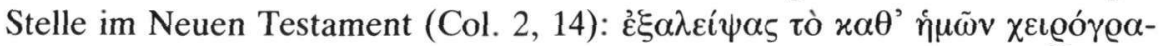
pov, was sich auf die Sündenschuld der gesamten Menschheit bezieht ${ }^{25}$. Was zur Zeit des frühen Christentums galt, hat sich im Byzantinischen Jahrtausend nicht geändert. Nach volkstümlicher Auffassung war das, was man am ehesten von einem "Dokument" bzw. von einem beschriebenen Blatt Papier zu erwarten hatte, die Einforderung einer Schuld. So heißt es noch bei Georgillas

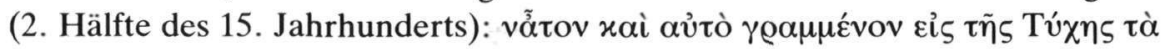
$\chi \propto \varrho \tau \iota \alpha ́$. Die "beschriebenen Blätter" sind das Schuldbuch der Tyche; auf deren wichtige Rolle für unser Thema werden wir bald zurückkommen ${ }^{26}$.

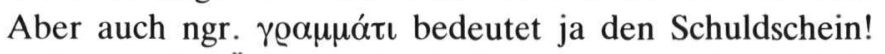

Dieses für Ägypten durch Tausende von Papyri belegte Verhältnis der Bürokratie zum Volk hat sich in den übrigen Teilen des Byzantinischen Reiches auch nach dem Verlust der wichtigen Ostprovinzen durch den Vormarsch der Araber fortgepflanzt. Schon die griechische Schrift der ägypti-

23. Zur Steuerflucht und zum Patronat in Ägypten vgl. J. Lalle mand, L'administration civile de l'Égypte de l'avènement de Dioclétien à la création du diocèse (284-382), Brüssel-Paris 1964, 18-20 und 226ff. H. B ra unert, Die Binnenwanderung. Studien zur Sozialgeschichte Ägyptens in der Ptolemäer- und Kaiserzeit, Bonn 1964, 165ff. und $299 \mathrm{ff}$.

24. R. Scholl, Sklaverei in den Zenonpapyri. Eine Untersuchung zu den Sklaventermini, zum Sklavenerwerb und zur Sklavenflucht, Trier 1983; zur Sklavenflucht 141-225.

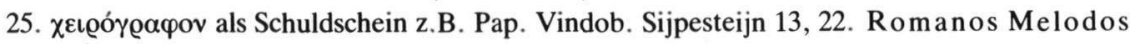
$26 \delta^{\prime} 1$; $56 \theta^{\prime} 3$. Zur Definition von $\chi \varepsilon \iota \varrho o ́ \gamma \varrho \alpha \varphi o v$ s. L. Wenger, Die Quellen des römischen Rechts, Wien 1953, 736f.

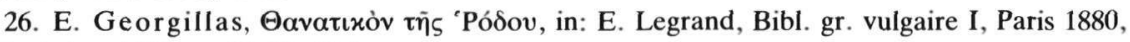
ND Athen 1974, v. 31 (S. 204). 
schen Behörden, die in ihrer Spätform, der Kursive des 6. und 7. Jahrhunderts, den Vorläufer einerseits der Minuskel und anderseits der Schrift der byzantinischen Kaiserkanzlei bildete, zeigt uns den engen Konnex zwischen früh- und mittelbyzantinischer Zeit, auch auf dem Gebiet der Verwaltung an. Die pompösen Formen im Wechsel mit winzigen Kümmerbuchstaben, wie sie uns in der byzantinischen Papyruskursive entgegentreten, sind das Vorbild für die Reservatschrift der byzantinischen Kaiserkanzlei mit ihren auffälligen Größenunterschieden der Buchstaben und ihren exzedierenden Schnörkeln; aber auch die ausgebildete Fettaugenmode des 13. und 14. Jahrhunderts lebte in dieser paläographischen Überlieferung.

Zwar änderten sich in Byzanz manche Namen, aber die Sache blieb im wesentlichen dieselbe. Kató $\lambda$ oyo 5 wurde nun eine ziemlich allgemeine Bezeichnung für Listen verschiedener Art, etwa die Stammrollen des Heeres, oder jene Kataster, die nach guter alter Art über die Personaldaten und Vermögensverhältnisse im Interesse der Steuerbemessung Auskunft gaben ${ }^{27}$. Es ist ein Merkmal der Entpersönlichung im Verkehr zwischen Behörde und Bürgern, daß der einzelne Steuerzahler bzw. Steuerschuldner mit dem Wort otíxos bezeichnet wurde, d.h. mit jener "Zeile" des Katasters, die seine Daten enthielt $^{28}$. Daß man hier keine "Steuergerechtigkeit" im modernen Sinn erwarten durfte, hat Franz Dölger seinerzeit treffend bemerkt: "Man wird nicht versuchen dürfen, an die byzantinische Steuerverfassung etwa mit unserem modernen Begriff der "Steuergerechtigkeit" heranzutreten. Vielmehr fehlt der Steuerhandhabung in Byzanz schon in den Grundsätzen jeder sozialpolitische Einschlag, und wenn in den Verordnungen der Kaiser zur "Gerechtigkeit" bei der Steuererhebung gemahnt wird, so bezieht sich dies natürlich nur darauf, daß die Einnehmer über das gesetzliche Maß nicht hinausgehen sollen. Dieses Maß aber war ohne jeden sozialen Leitgedanken festgesetzt ${ }^{29}$ ".

Die Parallele aus unseren Tagen sind die vielstelligen Nummern anstelle des Eigennamens in computerisierten Personaldokumenten.

Die wachsende Bedeutung der Schrift und des Kanzleiwesens von der Antike bis in die spätbyzantinische Zeit zeigt uns auch die Verwendungsweise des Verbums roá $\varphi \omega$ und einiger seiner Komposita.

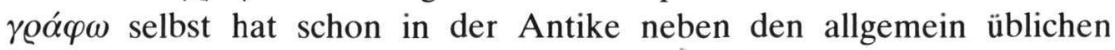
Bedeutungen schreiben oder anklagen folgende spezifische Verwendungsmöglichkeiten: jemanden mit einem schriftlichen Dokument in eine Funktion

27. N. G. Svoronos, Recherches sur le cadastre byzantin et la fiscalité aux $\mathrm{XI}^{\mathrm{e}}$ et $\mathrm{XII}^{\mathrm{e}}$ siècles: Le cadastre de Thèbes, Paris 1959 (= BCH 83 [1959] 1-166):

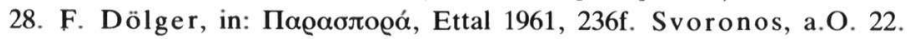

29. F. Dölger, Beiträge zur Geschichte der byzantinischen Finanzverwaltung, bes. des 10. und 11. Jahrhunderts, München 1927, ND Darmstadt 1960, S. 48f., A.4. 


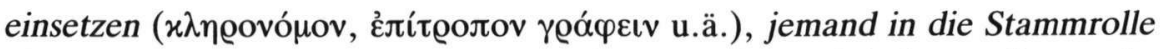
eintragen, aber auch allgemein registrieren. In byzantinischen volkssprachlichen Texten gibt es die militärische Bedeutung eintragen bei der Musterung

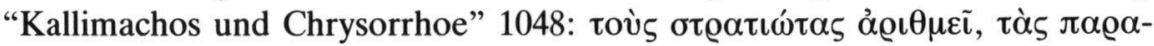

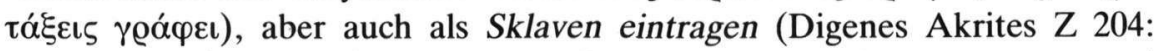

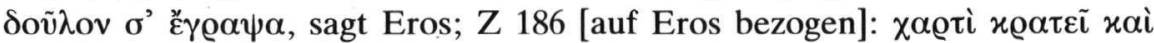

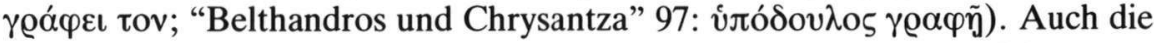

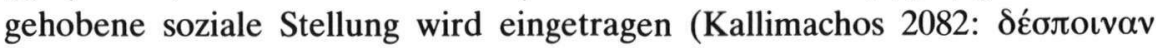

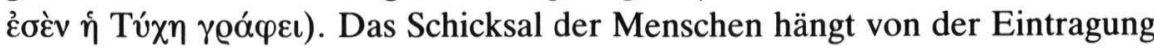

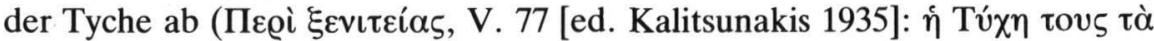

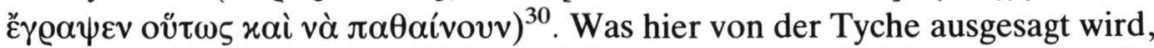
überträgt die theologische Diktion auf Gott, der siegreiche Märtyrer unter die

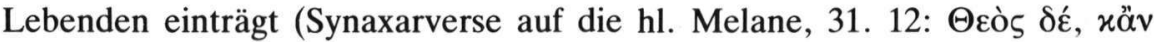

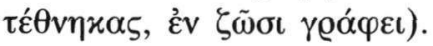

Die schicksalsträchtige Eintragung kann auch in Form von Inschriften

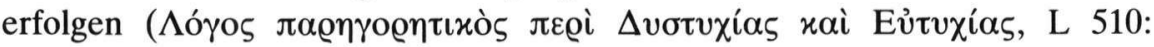

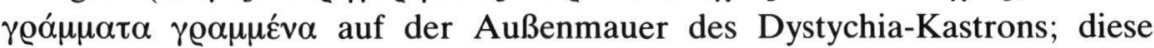
Inschrift bedeutet die Eintragung des Unglücklichen von der Hand der

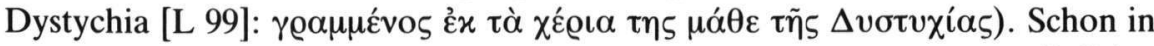
der Apokalypse entscheidet die Eintragung im "Buch des Lebens" (bıb

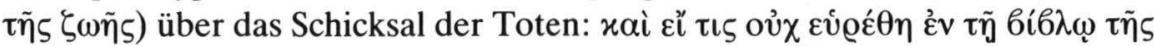

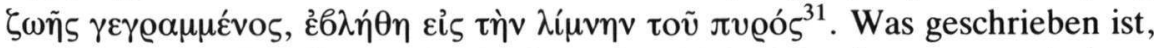

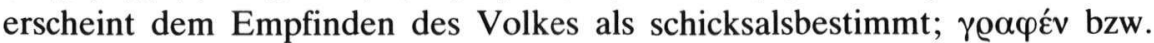

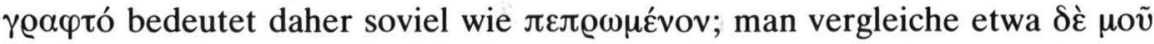

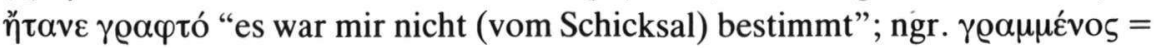

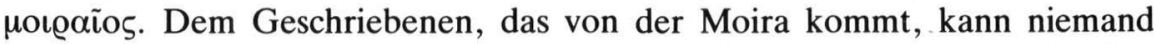

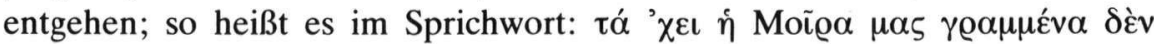

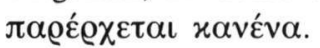

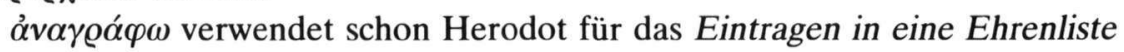
$(6,14 ; 8,90)$. In den Papyri heißt der in die Steuerliste Eingetragene häufig

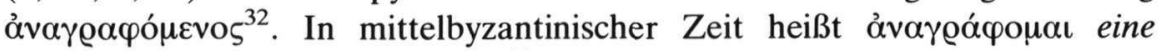

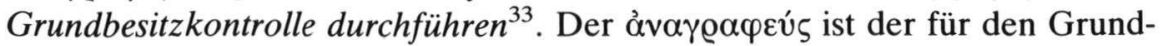
besitz und die Grundsteuer zuständige Kontrollbeamte ${ }^{34}$.

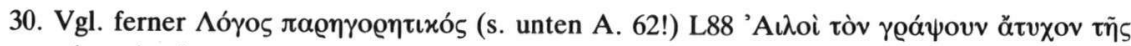

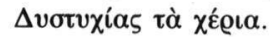

31. Apok. 20, 15; vgl. 17, 8; 20, 12; 21, 27.

32. z. B. Mitteis - Wilcken, a.O., Nr. 354, I 12 (a. 207); Pap. Vindob. Sijpesteijn (1963) 3, 5 (a. 325$)$

33. Actes de Lavra, edd. P. Lemerle et alii, I-IV, Paris 1970-1982: 6, 9 (a. 974?); 11, 17 (994); Actes de Docheiariou, ed. N. Oikonomidès, Paris 1984: 1, 20 (1037) u.v.a.

34. F. Dölger, Aus den Schatzkammern des HI. Berges, München 1948: 57, 33 B; 64, 1. Lavra 39 (1079); Docheiariou 2, 40 (1089) u.v.a. 


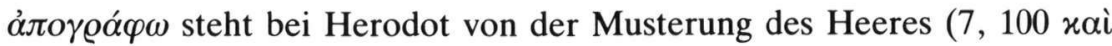

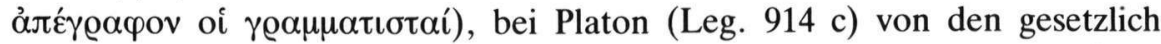
eingeführten Vermögenslisten. Die zum Geburtsjahr Christi genannte ảjo-

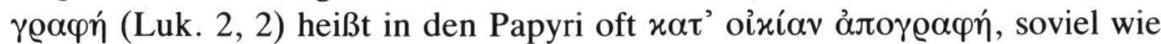

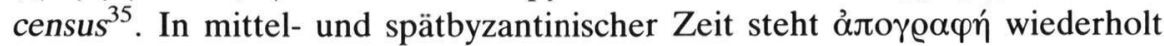
für das Klosterinventar ${ }^{36}$, vereinzelt auch für die Stammrolle bei der Muste-

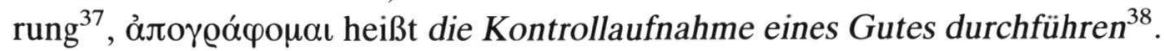
In theologischem Zusammenhang trägt Gott den Märtyrer unter seine

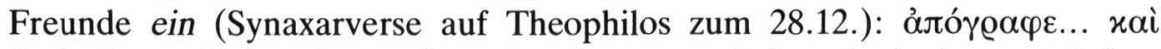

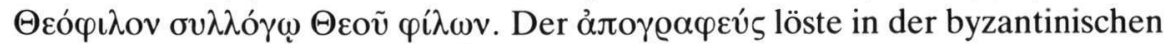
Spätzeit den ỏv $\alpha \gamma \varrho \alpha \varphi \varepsilon v ́ \varsigma ~ a b^{39}$.

$\delta \iota \alpha \gamma \varrho \alpha ́ \varphi \omega$ heißt schon bei Polybios $(6,12,6)$ in die militärische Stammrolle eintragen. Romanos Melodos (39 $\left.ı \eta^{\prime} 10\right)$ verwendet es für einen Toten im

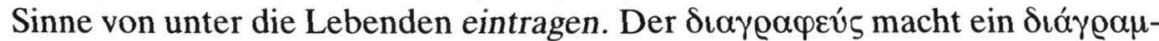
$\mu \alpha$, eine Steueraufstellung; die $\delta \iota \gamma \varrho \alpha \varphi \eta$ war die byzantinische Kopfsteuer ${ }^{40}$.

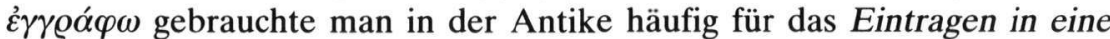
Bürgerliste $^{41}$, aber auch in eine Liste von Schuldnern ${ }^{42}$. Zahlreiche Beispiele finden sich in den Papyri ${ }^{43}$. ${ }^{\prime} E \gamma \gamma \varrho \alpha \varphi o v$ lebte in byzantinischer Zeit als eine den Menschen in ihre Gewalt nehmende Liste im Bereich des Eros fort:

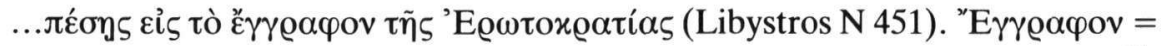
Urkunde findet sich in allen mittel- und spätbyzantinischen Jahrhunderten ${ }^{44}$. Theologisch verstanden werden Märtyrer unter die Geretteten eingetragen (Synaxarverse auf Sositheos zum 9.12.): $\Sigma \omega \sigma i ́ \theta \varepsilon o v ~ \sigma \omega \theta \varepsilon i ̃ \sigma \iota ~ \varepsilon ้ \gamma \gamma \varrho \alpha \varphi \varepsilon, \Lambda o ́ \gamma o \zeta$.

$\dot{\varepsilon} \pi \iota \gamma \varrho \alpha ́ \varphi \omega$ hat neben den geläufigen Bedeutungen daraufschreiben, eine Inschrift anfertigen, ein Dokument unterschreiben schon in der Antike die einschlägigen Bedeutungen: in die Bürgerliste eintragen (Thuk. 5, 4), zur Vermögensschätzung eintragen (Arist., Oikon. 2, 29), in die Steuerschuldliste

35. z. B. Mitteis - Wilcken, a.O. I 1, 225ff.; Pap. Vindob. Sijpesteijn 24 und 25. Vgl. Sh. LeRoy Wallace, Taxation in Egypt from Augustus to Diocletian, Princeton 1938, 96-115.

36. Lavra 61, 13 (1141); 93, 1 (1302); Docheiariou 22, 9 (1344); 23, 1 (1344).

37. Dukas, S. 91, 21 ed. Grecu.

38. Lavra 107, 11.30 (1319).

39. Dölger, Schatzkammern 61, 23 (1321); 32, 29 (1429); 66-79 (Praktika); Docheiariou 18, 6 (1337); 23, 26f. (1344).

40. Mitteis - Wilcken, a.O. I 1, 221; J. M. Diethart, JÖB 30 (1981) 51f.; Corp. Pap. Rain.

VIII, Gr. Texte V, Wien 1983, Nr. 79, 2.3.

41. z.B. Aristot., Pol. 1275 a 15; Dem. 39, 5.

42. Thuk. 1, 132; Plat., Leg. 784 d; Aristot., Ath. 48, 1; Dem. 25, 4; 43, 71.

43. Pap. Vindob. Sijpesteijn 2, I 7; II 9 (a. 339); Pap. Hermupolis, ed. B.R. Rees, London 1964, Nr. 21, 12.14 (a. 346); 31, 22.25 (6 Jh.).

44. Lavra 41, 4 (1081); 59, 58 (1110); Docheiariou 14, 9 (1314); 48, 2.30 (ca. 1381). 
eintragen (Andok. 1, 77). Bei Romanos steht غ̇лıү@á $\varphi \omega$ für sich jemand anschließen (39 $\left.\varepsilon^{\prime} 10\right)$, in spätbyzantinischen Urkunden für unterschreiben ${ }^{45}$.

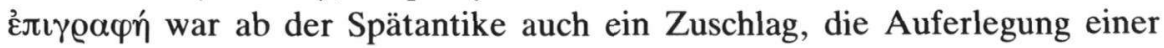
jährlichen besonderen Leistung.

$\pi о \lambda \iota \tau о \gamma \varrho \alpha \varphi \tilde{\omega}$ finden wir antik im Sinne von jemand als Bürger einschreiben, ihm das Bürgerrecht verleihe ${ }^{46}$. Im christlichen Sinn verstand man

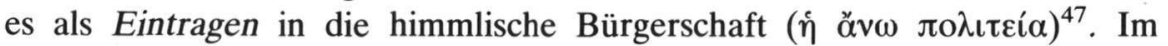
byzantinischen Roman lesen wir bei Eustathios Makrembolites (III 8): Hysminias wird Bürger von Aulikomis aufgrund eines von Eros stammenden (?)

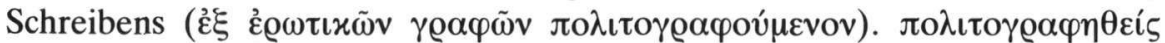
steht im Andrias des Nikephoros Blemmydes (159 Hunger-Ševčenko).

$\dot{\varepsilon} \pi \iota \gamma \varrho \alpha ́ \varphi \omega$ hat aber auch mit dem Lebensschicksal des Menschen, mit seiner Versklavung und mit seiner Freiheit zu tun: auf der einen Seite wird es für die

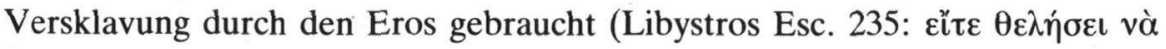

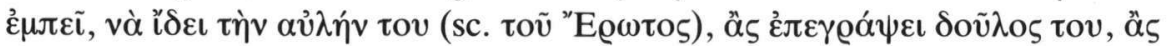

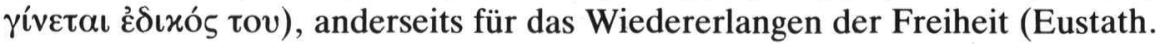

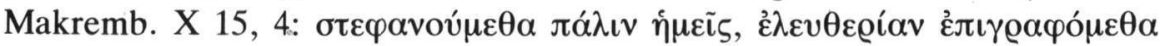

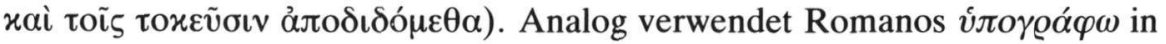
Verbindung mit ắqฮov (= Absolution) $\left(28 \theta^{\prime} 8 ; 56 \theta^{\prime}\right.$ 2: Christus, der die

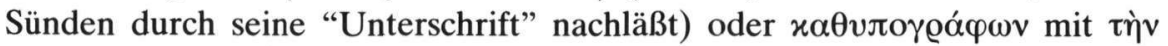

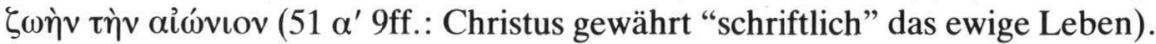

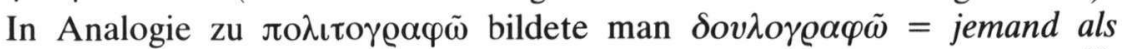
Sklaven eintragen, ihn durch Eintragung in eine Liste zum Sklaven machen ${ }^{48}$. Das Wort ist nach den Lexika nicht vor dem 12. Jahrhundert bezeugt; die ältesten Belege finden sich im Roman des Eustathios Makrembolites. Zwar ist dieser Text für gebildete Leser gedacht und in Hochsprache gehalten; das

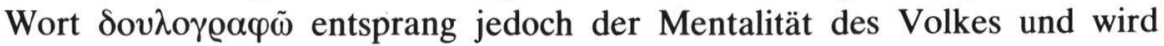
deshalb in volkstümlichen bzw. volkssprachlichen Werken auch früherer Jahrhunderte vorhanden gewesen sein. Wahrscheinlich liegt es nur an den besonderen Überlieferungsverhältnissen der volkssprachlichen griechischen Literatur -die ältesten erhaltenen Texte stammen aus dem 12. Jahrhundert!-,

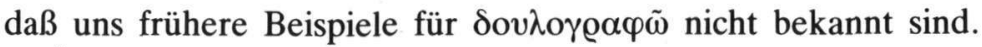

Über ein Dutzend Belege stehen in dem Roman "Hysminias und Hysmine"; zumeist ist es Eros, der die Versklavung durchführt. Das ganze

45. Lavra 89 B verso 22 (1298); Docheiariou 42 verso 18 (1373), 54 verso 2 (1414). - In der Ilias

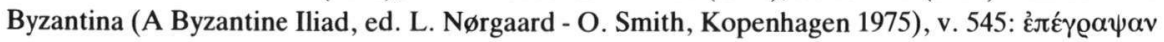

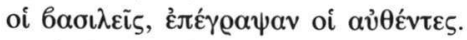

46. Polyb. 32, 7, 3; Diod. 11, 49, 3; 11, 72, 3; 11, 86, 3 .

47. Origen. Ioann. 19: PG 14, 565A.

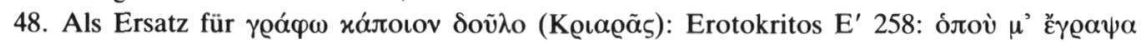

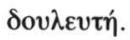


Geschlecht der Amphitrite (die Meereswesen) wird von Eros versklavt (II 9

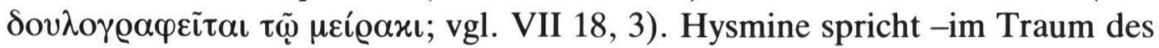
Hysminias- zu Eros: "Verschone den Hysminias, o König! Ich werde ihn Dir

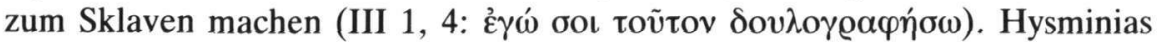
fühlt sich in körperlicher und seelischer Beziehung auf eine ganz neue Art von

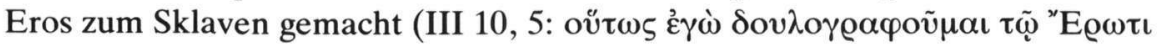

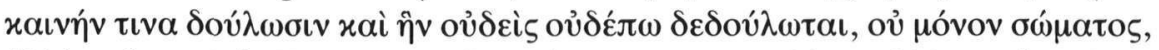

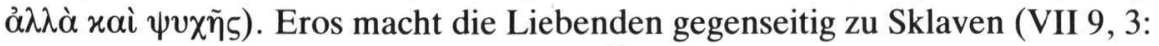

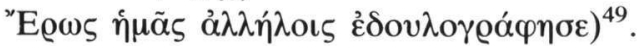

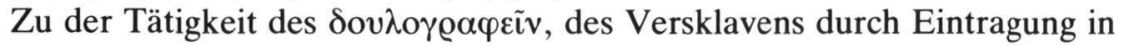

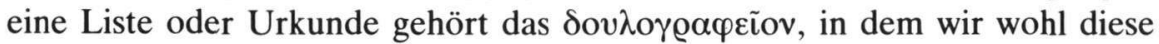
Urkunde zu sehen haben ${ }^{50}$. Eustathios Makrembolites verwendet das Wort dreimal: Der Seesturm, der die Liebenden gewaltsam trennt, wird mit einer Metapher wiedergegeben: Poseidon tilgt mit seinen Wogen die ganze

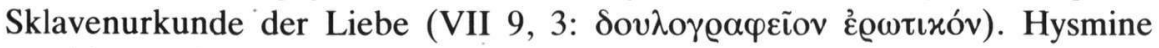
erzählt von ihren Schicksalen nach der Gefangennahme durch die Piraten

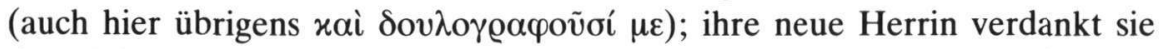
dem Meer, der Tyche und einer barbarischen Sklavenurkunde (XI 16:

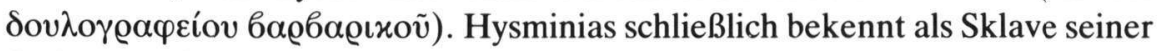
Beliebten, daß für ihn die Sklavenurkunde etwas Süß-saueres, aber Untilg-

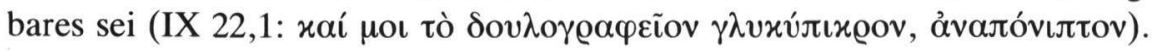

In "Kallimachos und Chrysorrhoe" erscheint Eros als derjenige, der das Innere entflammt und die harten Herzen versklavt (510f.). In starker Anti-

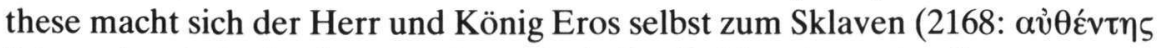

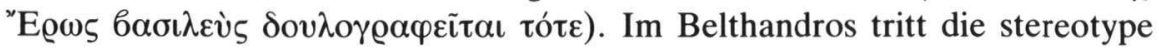

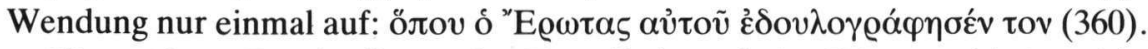

Eine nähere Beschreibung des Eros finden wir im Digenes Akrites; hier erscheint er als einflußreicher Kanzleibeamter, mit Tintenfaß und Papier versehen, um die Versklavungsurkunde ausstellen zu können ( $\mathrm{Z}$ 169: ... xai

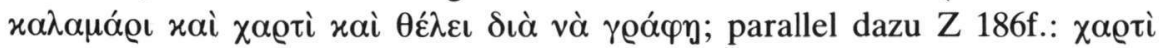

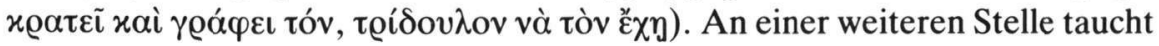

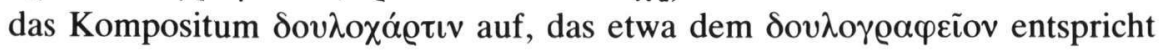

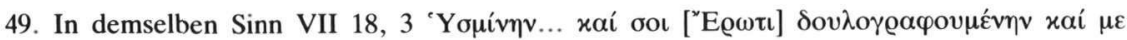

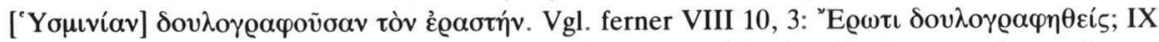

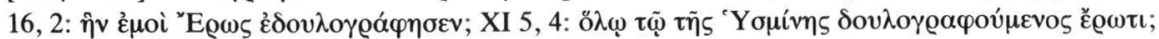
in diesem letzten Beispiel verliert der Eros seine Persönlichkeit und wird zu einer Funktion der Hysmine. Analog ist es in "Kallimachos und Chrysorrhoe" (V. 931) nicht der Eros als Personifikation, sondern die "Liebe auf den ersten Blick", die den Menschen versklavt: xai

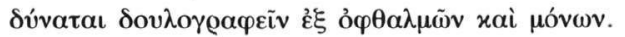

50. Kriaras, Lexikon s.v. versteht darunter eine Notariatsurkunde ( $\sigma v \mu b o ́ \lambda \alpha \iota)$, in der die Versklavung festgehalten ist. 


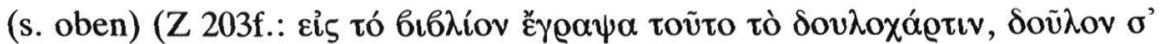

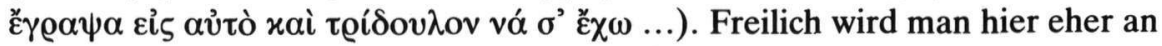

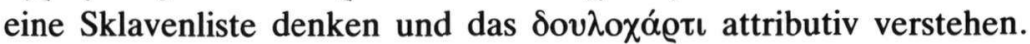

Neben Eros ist es vor allem die alte Schicksalsgöttin Tyche $=$ Moira, die den Menschen zum Sklaven machen kann. Auch sie wird unter dem Eindruck der Mentalität des Volkes in den Rahmen des Kanzleiwesens hineingestellt.

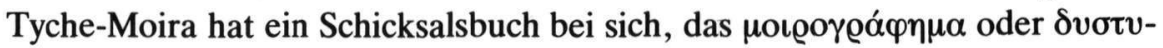

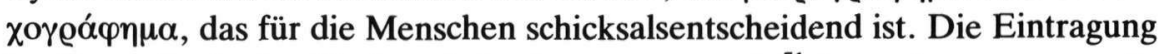

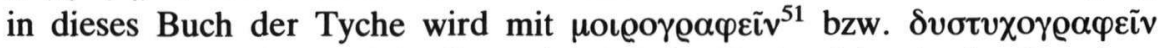
wiedergegeben: diese "Schreibertätigkeit" der Tyche führt in der Regel zu einer Abhängigkeit, einer Versklavung des Betroffenen. Chrysorrhoe warnt Kallimachos vor einem gemeinsamen Schicksal, das ihn nur in bleibendes

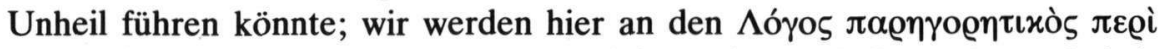

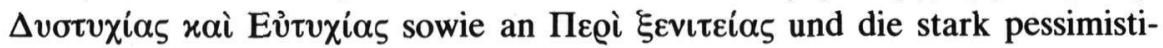
schen Züge dieser Dichtungen erinnert.

Kallimachos 717ff.:

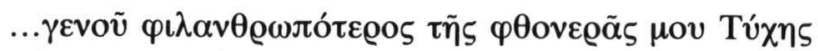

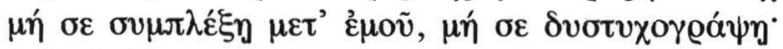

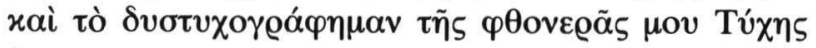

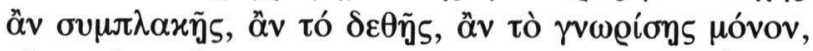

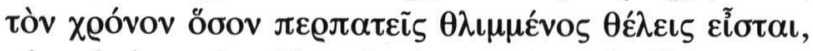

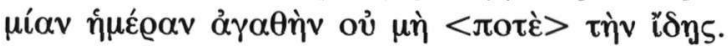

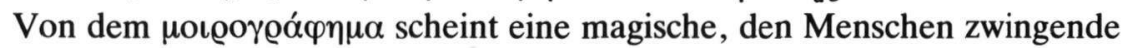
Gewalt auszugehen; das Verbum $\delta \varepsilon ́ \omega$, terminus technicus für den Bindezauber, ist verräterisch. Aber schon das bloße Kennenlernen oder zur Kenntnis nehmen ( $\gamma$ vwoírns) dieses Schicksalsbuches bedeutet die Verur-

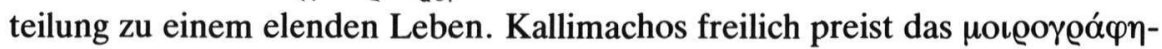
$\mu \alpha$-es kommt in drei Versen unmittelbar hintereinander je einmal vor!- der Tyche selig, weil es Chrysorrhoe befreit und ihn selbst mit ihr zum Sklaven

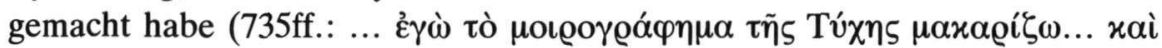

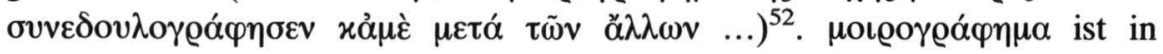
"Kallimachos und Chrysorrhoe" ein beliebtes Wort; es wurde auch von dem Rubrikator und Verfasser der Zwischentitel wiederholt verwendet (841.879.950.1198.1528).

Manchmal ist es eine Inschrift, die sich im Bereich der Tyche befindet oder von ihr selbst geschrieben wurde. In "Belthandros und Chrysantza" hängt die Zukunft der beiden Hauptpersonen von dem Inhalt zweier solcher Inschriften

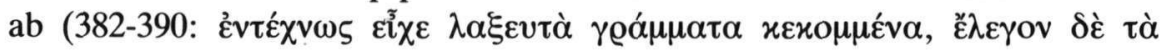

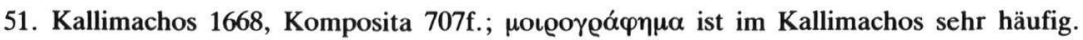

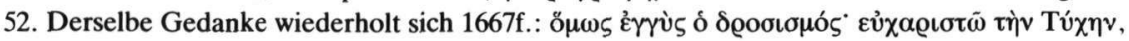

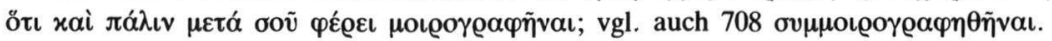




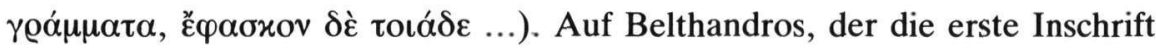
mehrmals liest, machen die $\gamma \varrho \alpha ́ \mu \mu \alpha \tau \alpha$ großen Eindruck. Später lernt er die zweite Inschrift kennen, die besagt, daß die beiden Liebenden vom Schicksal für einander bestimmt sind (419-425; hier findet sich die Tautologie $\dot{\eta}$

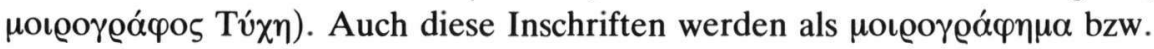

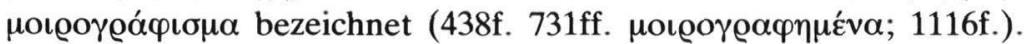

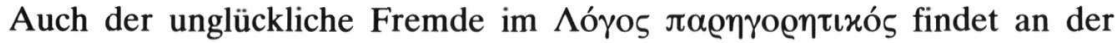
Außenmauer des Kastron der Dystychia eine Schicksalsinschrift (L 510f.:

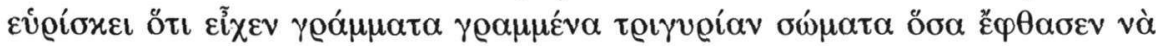

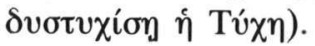

Wie sehr die Schriftlichkeit und das Kanzleiwesen die Vorstellungswelt der spätantiken Griechen und der Byzantiner beeinflußte, geht aus einer Reihe von Metaphern hervor, die aus diesem Begriffsfeld stammen. Das wichtigste Schreibgerät der Antike und des Mittelalters war der Kalamos, das gespitzte und in Abständen durch neues Spitzen wieder verwendbar gemachte Rohr. Schon der Psalmist vergleicht gesprochenes und geschriebenes Wort, wenn er seine Zunge mit dem Kalamos eines Schnellschreibers gleichsetzt (Ps. 44, 2: $\eta$

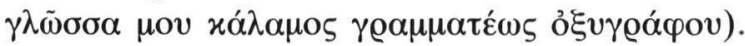

Romanos bediente sich dieses Zitats in seinem Kontakion auf den ungläubigen Thomas: Die Hand des Apostels, welche die Wunden Christi berühren durfte, wurde zum Kalamos eines Schnellschreibers, der den Gläubigen die Quelle des Glaubens aufschreibt (30 $\left.\gamma^{\prime} 1-4\right)$. Hier und an einer

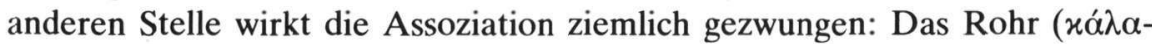
$\mu \mathrm{S})$, mit dem Christus aufs Haupt geschlagen wurde, verbindet sich bei Romanos gedanklich mit dem Schreibgerät ( $\left.\alpha^{\prime} \lambda \alpha \mu \circ\right)$ ), mit dem Christus die

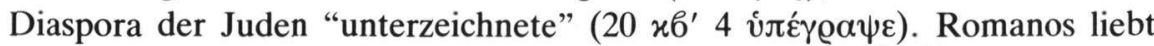
überhaupt Anspielungen auf Schrift- und Kanzleiwesen ${ }^{53}$. Ähnliche Metaphern finden sich auch in den Synaxarversen der Menäen. So erscheint der Märtyrer Eugraphos -wegen seines verlockenden Namens- als Schnellschreiber Gottes ${ }^{54}$, während Proterios als Kalamos eines Schnellschreibers im Kampf gegen die Irrlehre sein Martyrium besteht ${ }^{55}$.

Eine Personifikation des Schreibgerätes findet sich auch im Roman des Eustathios Makrembolites (IX 22, 1 spricht Hysminias als Sklave zu Hysmine:

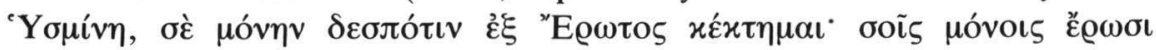

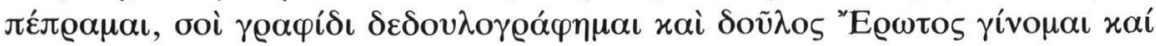

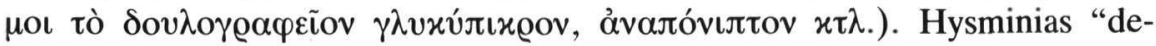
legiert" also die Unterdrückungsfunktion von Eros an Hysmine und sieht seine

53. H. Hunger, in Röm. Hist. Mitt. 25 (1983) 329-332.

54. Zum 10.12: E. Follieri, I calendari in metro innografico di Cristoforo Mitileneo (Subsid. Hagiogr. 62), 2 Bde, Brüssel 1980, hier II 104.

55. Zum 28.2.: Follieri, a.O. II 173. 
eigene Versklavung ganz unter dem Bild des Kanzleiaspekts. Die Geliebte wird zum Kalamos -hier $\gamma \varrho \alpha \varphi i \varsigma$ als allgemeine Bezeichung und als Femininum besser passend- wodurch die Sklavenurkunde, das kommt, das in Hysminias zwiespältige Gefühle ( $\gamma \lambda v$ xúлıxอov) wachruft. An

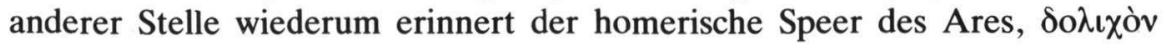

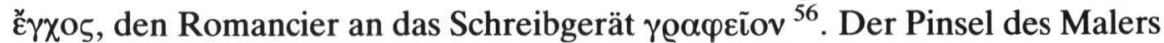
hingegen erscheint ihm wie die Lanze des Hermes ${ }^{57}$. Aber der byzantinische Literat geht auf diesem Weg noch weiter. Bei der Ekphrasis eines Monatsbildes geht es um die Darstellung eines Pflügers (IV 13): $\tilde{\eta} \delta \varepsilon$ $\gamma \varepsilon \lambda \alpha \iota \grave{\alpha}$

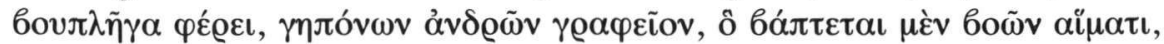
$\varkappa \alpha \lambda \lambda \iota \gamma \varrho \alpha \varphi \varepsilon \tilde{\imath} \delta \dot{\varepsilon} \tau \tilde{\eta} \gamma \tilde{\eta}$. Der Ochsenziemer des Bauern ist der Kalamos dieses verachteten Standes, der vom Blut der Ochsen gerötet -wie der Kalamos, wenn er in rote Tinte taucht- Zier- und Auszeichnungsbuchstaben schreibt

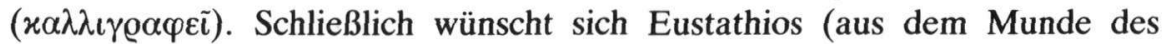
Hysminias) kurz vor dem Abschluß seines Werkes dessen Fortbestand (XI 22,

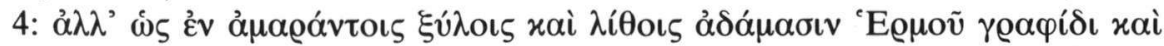

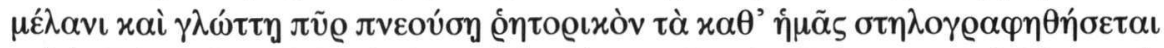
$\varkappa \tau \lambda$.) Die "Geschichte" der Liebenden soll mit Kalamos und Tinte als "rhetorisches" Werk, d.h. als Roman, wie auf Holz oder Stein aufgezeichnet werden. Die rhetorische Kunst (des Hermes) stellte man sich ja in Verbindung von Schrift und "feuriger" Rede vor. Daß die Schrift und ihre Werkzeuge so penetrant wie an den anderen Stellen des Romans in den Vordergrund treten, erscheint uns charakteristisch. E. Kitzinger macht mich darauf aufmerksam, daß die westlichen Evangelistenbilder im Vergleich zu den byzantinischen auf die Details der Schreibgeräte viel weniger Wert legen. "Schreibkästen" mit allem "Drum und Dran", wie wir sie auf byzantinischen Miniaturen, aber auch auf Mosaiken und Fresken häufig antreffen ${ }^{58}$, fehlen im Westen.

Die Macht des Buchstabens, d.h. der Schrift und bestimmter Texte und Urkunden, über den Menschen wurde breiten Schichten des Volkes in der Spätantike und in Byzanz gegenüber der Bürokratie und dem von ihr ausgebauten Kanzleiwesen bewußt. Es bedeutet ein Art von Sublimierung, wenn man in volkssprachlichen Texten, aber auch in Romanen, die gebildete Leser unter ihre Zielgruppen rechnen konnten, diese Macht der Bürokratie, die zugleich Willkür von der einen und Ausgeliefertsein von der anderen Seite implizierte, in die Sphäre des Dämonischen zu verlegen suchte. Die hervorstechenden Träger dieser Willkür und Macht waren -wie wir an zahlreichen Beispielen sehen konnten- Eros und Tyche. Eros, den schon Diotima im

56. Eustath. Makremb. II 3, 3.

57. Anspielung auf Hymn. Mercur. 460; Eustath. Makremb. IV 20, 3.

58. Vgl. H. Hunger, Evangelistenbilder in Handschriften, in: RbK 2 (Stuttgart 1967) 452-484. 
platonischen Symposion als Großen Daimon bezeichnete ${ }^{59}$, bedient sich bei der Unterwerfung der Menschen nicht nur seiner traditionellen Waffen Pfeil und Bogen, sondern auch der Attribute des Kanzlisten, Kalamos, Papier und Tinte, um seine Opfer zu versklaven. Freilich muß man zugestehen, daß die Ergebnisse dieser Gewaltausübung für die Menschen letztlich gar nicht so übel sind. Zwar können sie sich gegen die Waffen des Eros kaum zur Wehr setzen, aber schließlich kommen die Liebespaare, wenn sie auch noch so viel zu leiden haben, fast immer an ihr Ziel. Die Tyrannis des Eros ist eben keine reine Willkürherrschaft; wird er doch in Byzanz als Basileus aufgefaßt, der in einem kaiserlichen prunkvollen Schloß, einem Erotokastron, residiert ${ }^{60}$. Ein richtiger Kaiser konnte aber in Byzanz nur ein gerechter Kaiser sein!

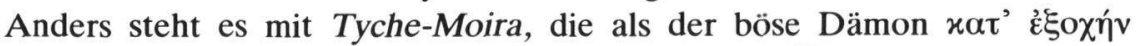

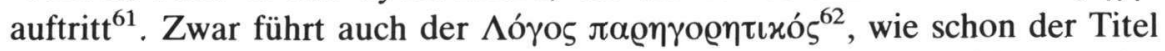
besagt, zu einem happy end; zugleich beobachten wir die Ambivalenz des Schicksals in der sinnfälligen Zerlegung der Tyche in zwei schwesterliche Gestalten, Dystychia und Eutychia. Aber die ausführliche Schilderung der jahrelangen Qualen des armen Fremden überwiegt schon umfangmäßig die kurzen sonnigen Augenblicke, die ihm gegönnt sind.

Die mühsame Wanderung des geplagten $\xi \xi \dot{\varepsilon}$ o $\varsigma$ zeigt, wie das ganze Menschenleben von der Dystychia und ihrem Kanzleibetrieb abhängt. Als "Kanzleichef" hat sie einen Gehilfen in Gestalt des Chronos, den sie mit ihrer eigenhändig geschriebenen Liste ausschickt, aus der hervorgeht, wen das Los

59. Plat. Sympos. 202 d-203 a.

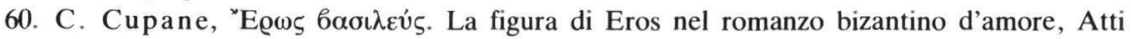
Accad. Sc. Lett. Arti Palermo IV 33 (1973/74) 243-297. Dies., Il motivo del castello nella narrativa tardo-bizantina, JÖB 27 (1978) 229-267, hier 242ff.

61. In "Kallimachos und Chrysorrhoe" wird die Tyche mit allen erdenklichen pejorativen

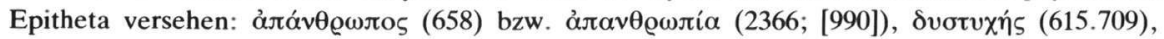

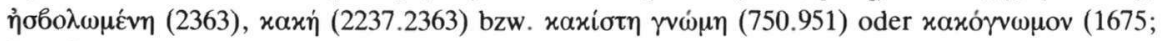

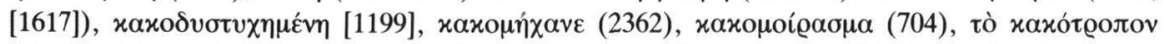

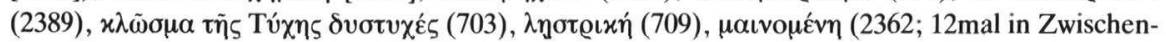

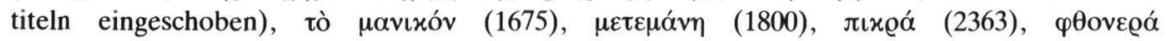
(611.615.709.717.719.1778.1803). Man kommt ihr mit Mißtrauen entgegen (589-591.1795f.). Einmal werden die unglücklichen Wendungen im Lebenslauf des Kallimachos kurz aufgezählt,

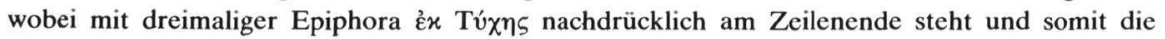
Hauptschuldige hervorhebt.

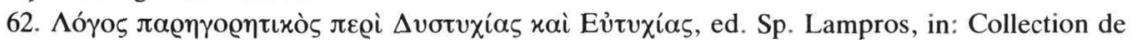
romans grecs, Paris 1880, 289-321 (=O); ed. Sp. Lampros, NE 3 (1906) 402-432 (=L). Dazu N. G.

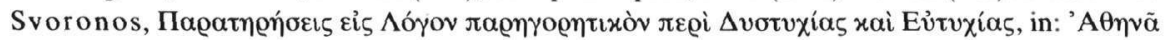

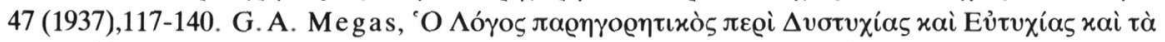

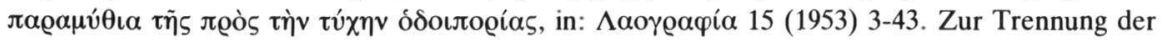
beiden Tychen s. auch C. Cupane, Note di iconografia tardobizantina: Tyche, Bios e Thanatos in Teodoro Meliteniotes, in: Byzance et les slaves. Études de civilisation. Mélanges Ivan Dujčev, Paris 1979, 109-119, hier bes. 113f. 
des Glücks oder des Unglücks getroffen hat. Die Ausdrucksweise erinnert an die Listen von Steuerschuldnern:

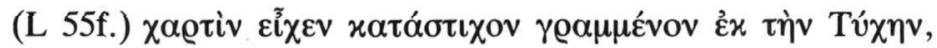

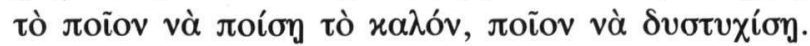

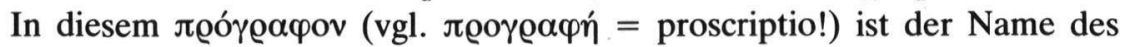
Fremden eingetragen, wie Chronos schnell feststellt:

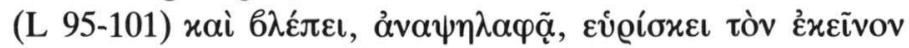

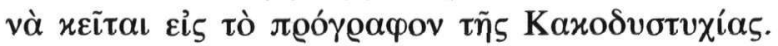

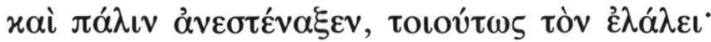

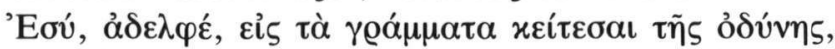

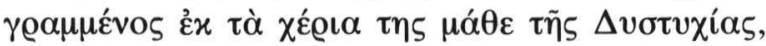

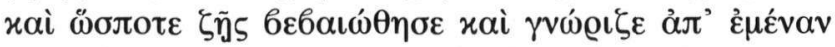

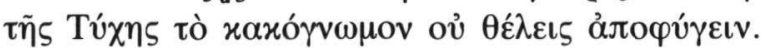

Aus diesen Worten des Chronos geht die Unwiderruflichkeit des Urteils und die lebenslängliche Abhängigkeit des Menschen von der übelwollenden Tyche hervor. Wer im alten Ägypten als Steuerschuldner in der analogen Situation war, versuchte durch Flucht in die Chora sich dem Zugriff der Behörden zu entziehen. - Der Fremde erhält von Chronos immerhin ein Empfehlungsschreiben (auf einem $\chi \alpha \varrho \tau i ́)$ an die Dystychia (L 485-507). Als er nach mühseliger Wanderung deren Schloß erreicht, findet er eine große Inschrift rings an der Außenmauer angebracht; es ist dasselbe Motiv wie in "Belthandros und Chrysantza" mit dem Erotokastron (s. oben).

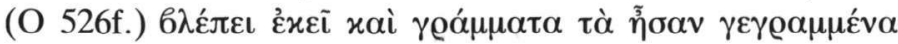

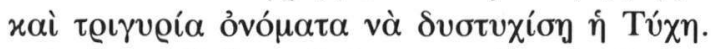

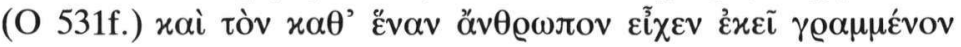

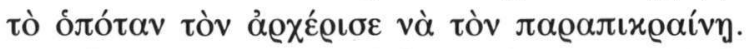

Tyche hat also ihre Namenliste auf der Außenmauer mit Datumsangaben versehen, von wann an sie begonnen hatte, jeden einzelnen zu quälen ${ }^{63}$. Am Ende seiner jahrelangen aufreibenden Unglücksstrecke wird der Fremde von der Dystychia endlich begnadigt. Aus diesem Anlaß gibt die Schloßherrin einem Diener den Befehl, den auf das Unglück festgeschriebenen Namen des Fremden auf der Außenmauer zu tilgen:

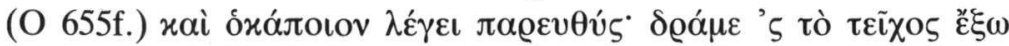

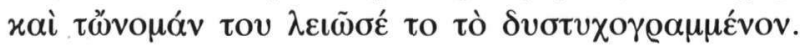

Wir bleiben weiterhin im Kanzleibereich. Tyche, die sich nunmehr aus einer Dystychia in eine Eutychia verwandelt, stellt dem Fremden eine Privilegurkunde mit Siegel aus:

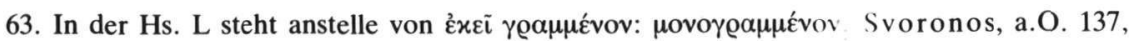

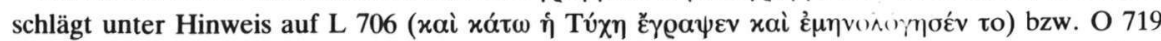

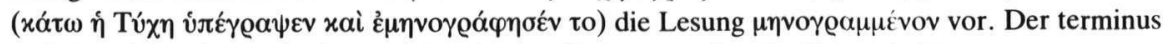
technicus Menologem bedeutet ja auch eine Datumsangabe als Unterschrift. 


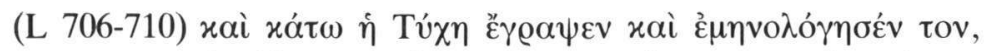

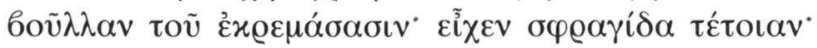

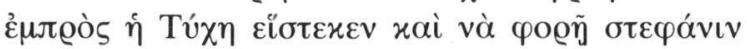

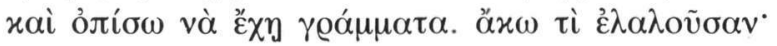

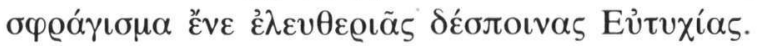

Die Urkunde wird mit Menologem unterschrieben ( $\dot{\mu} \mu \eta v o \lambda o ́ \gamma \eta \sigma \varepsilon v)$, ein Siegel wird angehängt (бoṽ $\lambda \lambda \alpha v$ und $\sigma \varphi \varrho \alpha \gamma i \delta \alpha$ stehen pleonastisch nebeneinander). Daß die gekrönte Tyche auf dem Avers des Siegels stehend zu sehen ist, hat der Autor offenbar von Kaisersiegeln mit der schlanken Stele des jeweiligen Herrschers übernommen. Die Siegellegende des Reverses

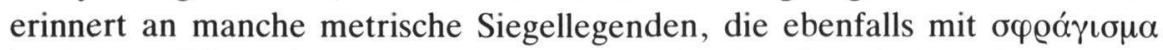
beginnen. Diese Legenden nennen zwar in der Regel den Namen des Siegelinhabers und die allgemeine Aufgabe des Siegels (Bestätigung der Urkunden), nicht aber einen bestimmten Einzelfall (wie hier $\dot{\lambda} \lambda \varepsilon v \theta \varepsilon \varrho\llcorner\tilde{\alpha} \varsigma$ ). Freilich könnte man zugunsten des Autors einwenden, Freilassungsurkunden auszustellen sollte eine, wenn nicht regelmäßige, so doch wiederholte Tätigkeit der Tyche $\operatorname{sein}^{64}$.

Obwohl die Freilassungsurkunde das Siegel der Eutychia trägt, erhält der Fremde von der Tyche (= Dystychia) ein Begleitschreiben an deren Schwester, die Eutychia, in dem sie mitteilt, daß sie ihn aus der "Unheilsliste" gestrichen, herausgenommen habe. Das hiebei gebrauchte Wort oxa $\lambda_{i v}$ (Stufe) dürfte die Stelle von otíxo૬ vertreten. Die Schuldnerliste ist kanzleiüblich in "Leiterform" angelegt, wobei jeder Name eine eigene Stufe besitzt;

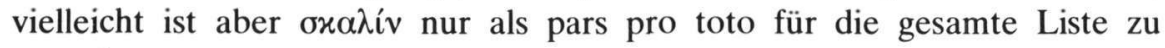
verstehen:

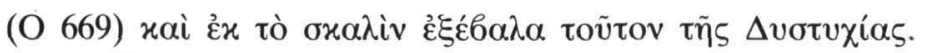

Man sollte meinen, daß der arme Fremde nun sein Ziel erreicht hat und endlich mit einem glücklichen Leben beginnen kann. Keineswegs: Zuvor muß ein solcher Mensch, der sich vom "Buchstaben" abhängig fühlt und alles von ihm befürchtet, seine Existenz sichern. So bittet er die Eutychia, ihn in ihre Liste einzutragen:

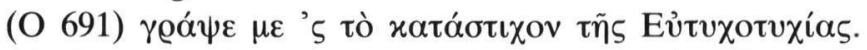

Wenig später hören wir aus dem Munde der Eutychia, daß sie diesen

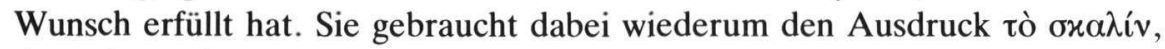
der mit xatáotıxo synonym zu sein scheint.

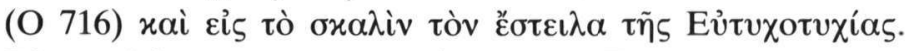

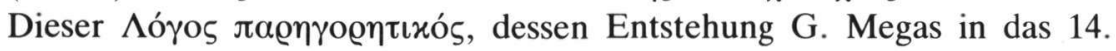
Jahrhundert setzen wollte, ist ein vorzügliches Beispiel für das Verhalten der Byzantiner gegenüber der Bürokratie: Geduldiges, jahrelanges Warten, bis

64. V. La ure nt, Les bulles métriques dans la sigillographie byzantine, Athen 1932. G.ZacosA. Veglery, Byzantine Lead Seals I/3, Basel 1972, S. 1919-1928. 
endlich lebenswichtige Wünsche erfüllt werden, sowie selbstverständliche Unterwürfigkeit gegenüber den mächtigen Beamten, von denen das eigene Schicksal abhängt. Die Proskynese vor dem "Kanzleichef" Tyche ist für unseren Fremden Pflicht und Gewohnheit ${ }^{65}$.

Welche Hilfe gab es für den "kleinen Mann" in Byzanz angesichts seiner oft schwierigen Lage gegenüber einer harten, ihm kaum zugänglichen Behörde, vor allem gegenüber dem einzelnen Steuereintreiber, Finanzbeamten oder Richter? Wer in der Hauptstadt lebte oder sie aufsuchen konnte und zudem

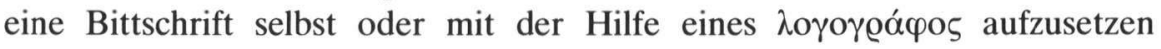
verstand, konnte auf den Rechtsschutz, die bo $\theta \varepsilon \varepsilon \_$seitens des Kaisers, hoffen. Was tat die überwiegende Zahl derer, die sich nicht in dieser günstigen Position befanden? Die Kirche, die einen Großteil der sozialen Fürsorge seit den frühen Jahrhunderten dem Staat abgenommen hatte, war nicht in der Lage, generell für Abhilfe zu sorgen. Im besten Fall konnten gute Oberhirten, Metropoliten und Bischöfe, innerhalb ihres Kompetenzbereichs gewisse Linderungen veranlassen und Übergriffe abwehren. Johannes Chrysostomos, Johannes der Barmherzige (Eleemon) von Alexandreia und Patriarch Athanasios I. von Konstantinopel seien stellvertretend genannt. Zumeist wird man sich auf tröstenden Zuspruch in christlichem Sinn beschränkt haben. Dieser Trost ging wohl in die Richtung der Erzählung vom reichen Prasser und vom armen Lazarus: Ausgleich der sozialen Ungerechtigkeit im Jenseits durch Bestrafung des Schuldigen und Herzlosen und durch Belohnung des unschuldig Unterdrückten. Schon in der "Sapientia Salomonis" (6, 6 bzw. 8$)$ lesen wir:

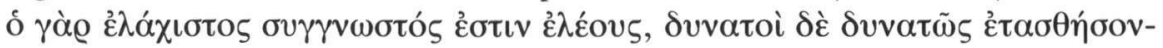

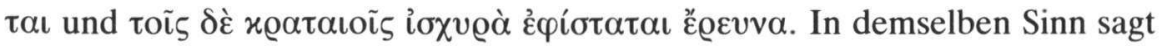

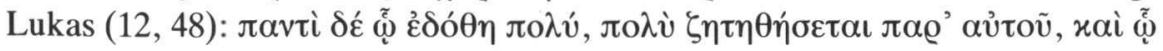

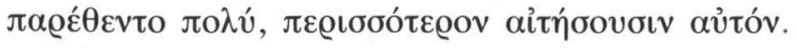

Die Angst vor dem Tod und dem Schicksal des Menschen nach dem Tod hat sich seit Jahrtausenden in verschiedenen eschatologischen Vorstellungen niedergeschlagen. Es ist höchst charakteristisch, daß in der Spätantike und in Byzanz diese Angst mit dem Schreckbild der übermächtigen Bürokratie

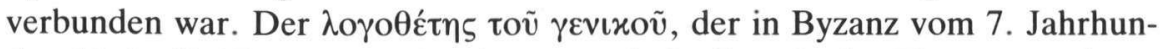
dert bis in die Komnenenzeit seine zentrale Stellung in der Finanzverwaltung zu wahren wußte und über einen umfangreichen Personalstand verfügte ${ }^{66}$, und sein $\lambda$ o $\gamma \circ \theta \varepsilon \dot{\varepsilon} \sigma \circ v$ waren der Inbegriff jener unangreifbaren Macht, die von dem

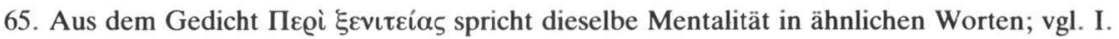

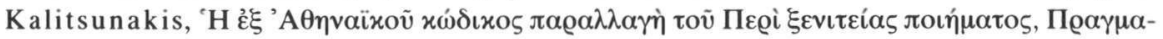

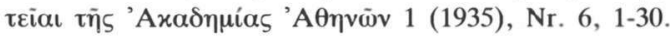

66. F. Dölger, Beiträge zur Geschichte der byzantinischen Finanzverwaltung, bes. des 10 . und 11. Jahrhunderts, München 1927, ND Darmstadt 1960, $20 f$. 
einfachen Bürger Rechenschaft verlangte, d.h. Steuern und Zölle einhob. Das Verbum $\lambda \circ \gamma \circ \theta \varepsilon \tau \varepsilon \dot{\varepsilon} \omega$ (= zur Rechenschaft ziehen) übertrug der verängstigte Bürger aus seinem geplagten Alltag in den eschatologischen Bereich. Man stellte sich vor, daß die Seele nach der Trennung vom Leib eine Zone des Schreckens zu durchschreiten habe, in der sie den Zwangsmaßnahmen der dämonischen Mächte der Luft ausgesetzt sei. So spricht z.B. Anastasios

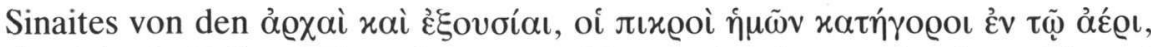

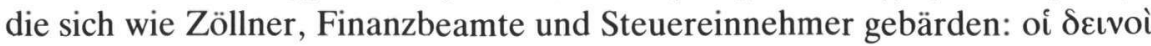

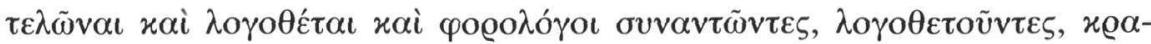

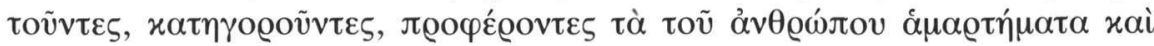
$\chi \varepsilon\llcorner\varrho o ́ \gamma \varrho \alpha \varphi \alpha x \tau \lambda$.

Es geht zwar um die Sünden der Menschen, für die sie zur Rechenschaft gezogen werden, aber das Milieu entspricht jenem der gefürchteten irdischen Finanz- und Zollbehörden; Rechenschaftslegung und Schuldschein gehören dazu $^{67}$.

Auch in der Vita des Elias Spelaiotes wird dieser beklemmende Weg der Seele ins Jenseits geschildert ${ }^{68}$. In der Ekstase sieht der Heilige seine eigene

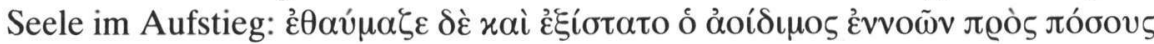

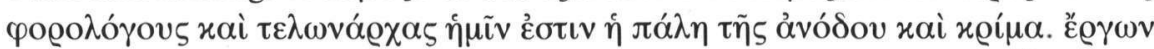

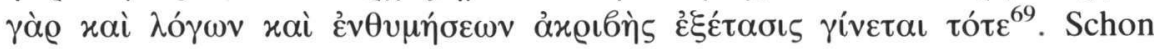
vorher wird der schwierige Aufstieg der Seele mit einem Psalmzitat

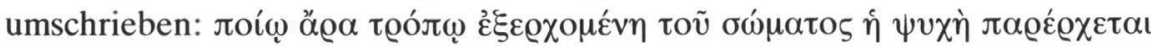

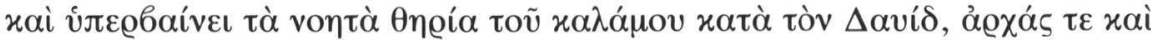

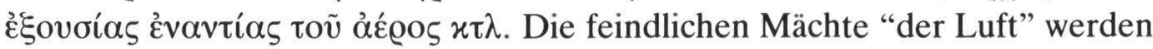
hier als "intelligible Bestien des Kalamos" eingeführt. Ps. 67, 31 ruft der

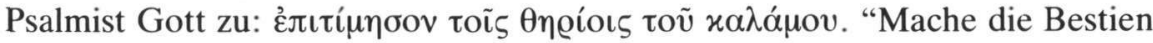
des Kalamos mundtot" ${ }^{\prime 70}$. In den Psalmenkommentaren wird zu dieser Stelle auf wilde Tiere, insbesondere Löwen, hingewiesen, die im Schilf auf ihre

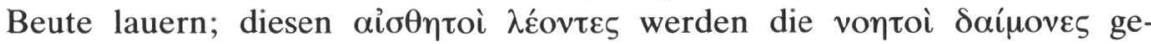
genübergestellt, denen sich die Seele ausgeliefert sieht. Theodoretos von

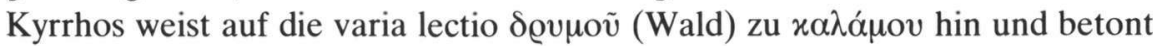

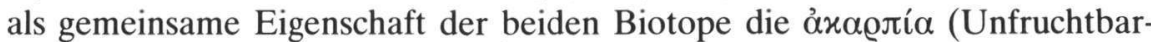
keit ${ }^{71}$. Aber schon Didymos der Blinde bezieht die "Bestien des Kalamos"

67. Anastasios Sinaites, Sermo in defunctos, PG 89, 1200C 6-10.

68. Hinweis auf diese und die folgende Stelle bei C. Mango, Byzantium. The Empire of New Rome, London 1980, 164f.

69. AASS Sept. III 876 F.

70. Das غ̇лıт́́ Euthymios Zigabenos, PG 128, 680D.

71. Theodoretos von Kyrrhos, Interpret. in Psalmos, PG 80, 1396B: ह̌vil $\delta \dot{\varepsilon} \tau \bar{\omega} v$

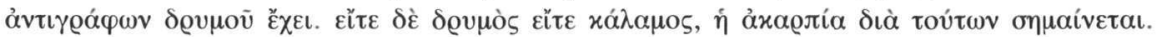

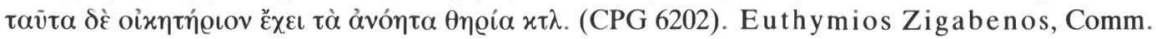




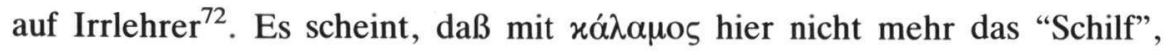
sondern das Schreibrohr gemeint ist, zumal für die Kennzeichnung der

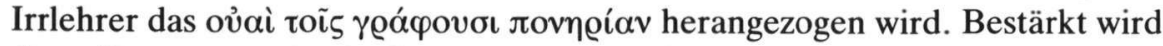
diese Vermutung durch die entsprechende Stelle im Psalmenkommentar des

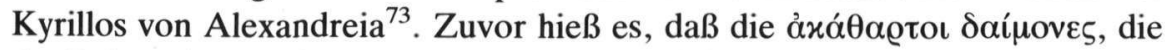

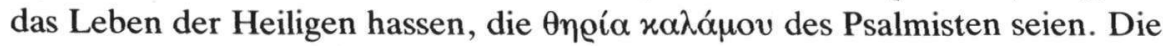
Bezeichnung stamme von einem Ort namens Kalamos bei Jerusalem, wo im dichten Schilf Löwen und andere wilde Tiere auf die Wanderer lauern. Im

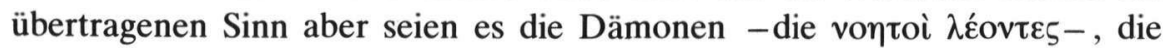

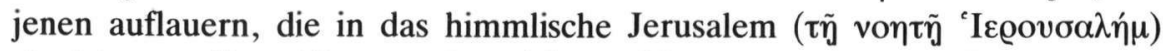
einziehen wollen. Unter toṽ $x \alpha \lambda \alpha \dot{\alpha} \mu o v \theta \tilde{\eta} \varrho \varepsilon \varsigma$ versteht der Kommentator jedoch auch die Erfinder von Häresien, die "Entstelltes, Verdrehtes auf-

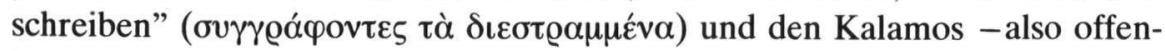
bar das Schreibgerät- wie einen Zahn benützen, um mit ihm die Seele naiver Menschen zu "verzehren".

Nach den oben angeführten Beispielen für Metaphern von xá $\lambda \alpha \mu \circ \zeta$ erscheint es mir ziemlich sicher, daß auch hier mit den $\theta$ dämonischen Mächte in ihrer Funktion als "Kanzleibestien" zu verstehen sind. Dazu paßt auch die Formulierung des Leontios von Neapolis in seinem Bios

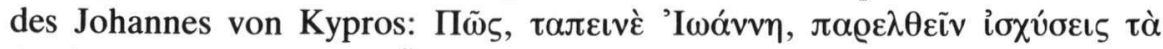

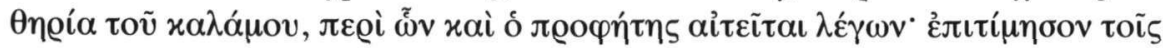

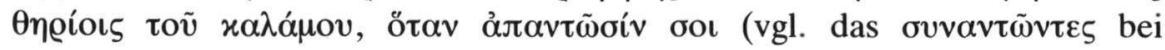

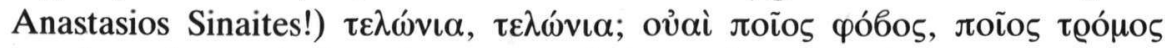

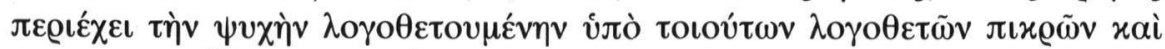

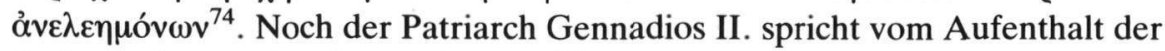
Seele in den Zollstationen der Luft ${ }^{75}$.

Für Romanos Melodos habe ich an anderer Stelle zu zeigen versucht, daß er

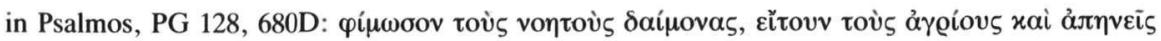

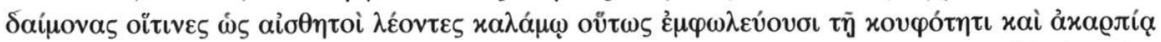

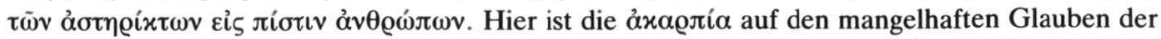
Menschen übertragen.

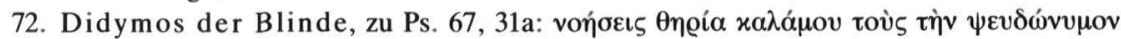

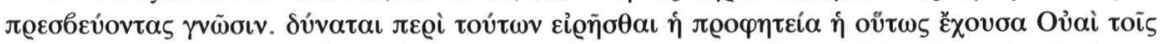

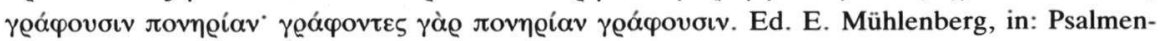
kommentare aus der Katenenüberlieferung, Bd. 2, Berlin - New York 1977, 73 (CPG 2551).

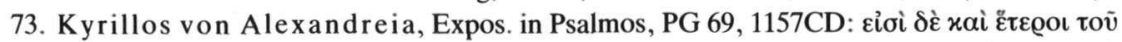

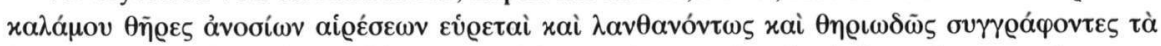

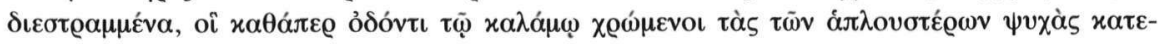
öiovoเv (CPG 5202).

74. A. J. Festugière, Léontios de Néapolis. Vie de Syméon le Fou et Vie de Jean de Chypre, Paris 1974, S. 395, Z. 71-76; vgl. auch S. 396,78ff.

75. Georges Scholarios, CEuvres complètes, I, Paris 1928, S. 513, 12: $\grave{\eta} \tau \varepsilon \lambda \omega v i \omega v$

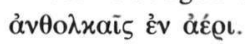


als Seelsorger und Prediger seiner Herde in ihren Ängsten und Komplexen Beistand leistete, indem er immer wieder Elemente des Kanzleiwesens und verschiedene Situationen des Verkehrs mit der Bürokratie in seinen Kontakia in die himmlische Sphäre versetzte ${ }^{76}$. Der "kanzleigemäße" Verkehr zwischen Gott und Mensch ging aber auch in die byzantinische Buchmalerei ein. So erscheint im Cod. Iviron 5 (13. Jh.) das doppelte Stifterbild -Christus und Johannes Chrysostomos Maria und der Stifter Johannes - in Form einer "Kanzleiszene" 77 . Maria übt ihr Amt als $\mu \varepsilon \sigma i \tau \iota \varsigma$ wie ein غ̇ंì $\tau \tilde{\omega} v v \delta \varepsilon \eta ́ \sigma \varepsilon \omega v$ mit einer Schriftrolle aus, welche die Sündenvergebung und langes, glückliches Leben für ihren Schützling beinhaltet; der Text der Schriftrolle beginnt mit

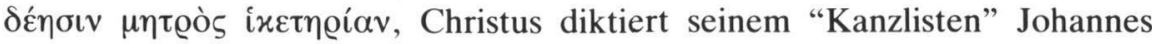
Chrysostomos die "Lysis", welche die Sündenvergebung für dessen Namensvetter (den Stifter) enthält. Die unmittelbare "günstige" Erledigung der Bitte erinnert wiederum an Romanos, bei dem Maria dem göttlichen Kind in der

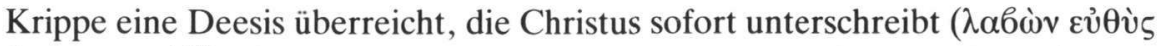
$\dot{v} \pi \hat{\varepsilon} \gamma \varrho \alpha \psi \varepsilon v)^{78}$. Christus tilgte nicht nur den menschlichen Schuldschein ( $\chi \varepsilon £ \varrho o ́ \gamma \varrho \alpha \varphi \circ v)$, wie schon im Neuen Testament vorgegeben, sondern er agiert bei Romanos als gerechter und milder, menschenfreundlicher Basileus, er hält für die Menschen seit Ewigkeit die schönsten "Schenkungsurkunden" bereit und ist für jeden, auch den Kleinsten und Bescheidensten, jederzeit ansprechbar, ohne auf eine besondere Bittschrift zu warten. Romanos faßt seinen Standpunkt gegenüber der Herrschaft des "Buchstabens" in dem Satz zusammen: "Denn dem sittlichen Adel können Papier und Tinte nichts anhaben"79.

Sind die geschilderten Verhältnisse auf die Spätantike und auf Byzanz beschränkt geblieben? Mutatis mutandis können wir Ähnliches auch heute noch beobachten. So heißt es in einer Wiener Pressenotiz (Zeitung "Die Presse" v. 12.6.1984): "Schier unersättlich scheint der Datenhunger (der Behörde): Volkszählung, Mikrozensus, Arbeitsstätten-, Haus- und Wohnungszählung, Konsumerhebung, Index- und Inflationsberechnungen usw". All das ergibt beim Österreichischen Statistischen Zentralamt 7 Milliarden

76. H. Hunger, Romanos Melodos, Dichter, Prediger, Rhetor - und sein Publikum, JÖB 34 (1984) 15-42, hier 39-42; italienische Fassung: Röm. Hist. Mitt. 25 (1983) 305-332, hier 329-332.

77. H. Belting, Das illuminierte Buch in der spätbyzantinischen Gesellschaft, Heidelberg 1970, 35f. und Fig. 23.24.

78. 2 เ $\gamma^{\prime}$ 1-3; vgl. auch 8 เ $\gamma^{\prime}$ 1-10. JÖB 34 (1984) 40. Zeitlich und räumlich weit entfernt sind jene Darstellungen der Verkündigung an Maria, in denen der Erzengel ein Schriftstück - versiegelte Urkunde bzw. Rolle- in der Hand hält, ein Motiv, das in hochmittelalterlichen Fresken des europäischen Westens häufig auftritt. Vgl. Th. Hach, Die Verkündigung Mariä als Rechtsgeschäft, Christl. Kunstblatt für Kirche, Schule und Haus 23 (1891) 165-169.178-183. Den Hinweis auf diesen Artikel verdanke ich meinem Kollegen und Freund H. Buschhausen.

79. Romanos 44 เ6' 5 . 
Informationseinheiten im Jahr, und das bei einer Bevölkerung von wenig über 7 Millionen.

Trotz dem gesetzlich vorgeschriebenen Datenschutz steckt dem Bürger die Angst vor diesen Erhebungen in den Knochen. So sagte der Präsident des Statistischen Zentralamtes: "Weil eine gewisse Angst da ist, gibt es bei uns ja auch keine ordentliche Einkommensverteilungsstatistik". Die Verweigerung einer Antwort auf Fragen des Amtes wird mit Geldstrafen belegt, die progressiv bis zu 30.000.- ö.S. ansteigen. (Zitat des genannten Präsidenten): "Die Leute glauben dann, sie kommen mit einmal 500.- Schilling weg. Aber sie werden so lange bestraft, bis sie endlich einmal Auskunft geben".

Jeder Kommentar erübrigt sich. 